\title{
Intraguild predation and competition impacts on a subordinate predator
}

\section{Bjorklund, Heidi}

2016-05

Bjorklund, H , Santangeli , A , Blanchet , F G , Huitu , O , Lehtoranta , H , Linden , H , Valkama , J \& Laaksonen , T 2016 , ' Intraguild predation and competition impacts on a subordinate predator ' , Oecologia , vol. 181 , no. 1 , pp. 257-269 . https://doi.org/10.1007/s00442-015-3523-z

http://hdl.handle.net/10138/175688

https://doi.org/10.1007/s00442-015-3523-z

other

acceptedVersion

Downloaded from Helda, University of Helsinki institutional repository.

This is an electronic reprint of the original article.

This reprint may differ from the original in pagination and typographic detail.

Please cite the original version. 
1 This is the last submitted version of the article that was published in Oecologia (2016) 181:

2 257-269, DOI 10.1007/s00442-015-3523-z

3 The final publication is available at link.springer.com/article/10.1007/s00442-015-3523-z

4

5

6

7

8

9

Intraguild predation and competition impacts on a subordinate predator

10 Heidi Björklund*, Andrea Santangeli, F. Guillaume Blanchet, Otso Huitu, Hannu Lehtoranta,

$13 *$ Contact information for the corresponding author:

14 Heidi Björklund

15 Finnish Museum of Natural History Luomus, P.O. Box 17, FI-00014 University of Helsinki,

16 Finland

17 heidi.bjorklund@helsinki.fi, +358-2941-28844

18 
${ }^{a}$ Finnish Museum of Natural History Luomus, P.O. Box 17, FI-00014 University of Helsinki,

${ }^{\mathrm{b}}$ Department of Biosciences, P.O. Box 65, FI-00014 University of Helsinki, Finland;

${ }^{c}$ Department of Mathematics and Statistics, McMaster University, 1280 Main Street West, Hamilton, Ontario, Canada L8S 4K1;

${ }^{d}$ Natural Resources Institute Finland, Suonenjoki Research Unit, Juntintie 154, FI-77600 Suonenjoki, Finland;

e Suomen metsäkeskus, Pohjois-Karjalan alueyksikkö, Poikolantie 2, FI-83900 Juuka, Finland;

${ }^{\mathrm{f}}$ Natural Resources Institute Finland, P.O. Box 2, FI-00791 Helsinki, Finland;

${ }^{\mathrm{g}}$ Department of Biology, University of Turku, FI-20014 Turku, Finland* Corresponding author: heidi.bjorklund@ helsinki.fi, +358-2941-28844¹

\footnotetext{
${ }^{1} \mathrm{HB}$ originally formulated the idea, HB, AS, JV, TL designed the study, OH, HLe, HLi provided the data, HB, AS, FGB, JV, TL contributed to methodology and analyses, HB performed statistical analyses and wrote the manuscript; all authors provided editorial advice.
} 


\section{Abstract}

36 Intraguild (IG) predation and interspecific competition may affect the settlement and success

37 of species in their habitats. Using data on forest-dwelling hawks from Finland, we addressed the impact of an IG predator, the northern goshawk Accipiter gentilis (goshawk), on the breeding of an IG prey, the common buzzard Buteo buteo. We hypothesized that the

40 subordinate common buzzard avoids breeding in proximity of goshawks and that interspecific

41 competitors, mainly Strix owls, may also disturb common buzzards by competing for nests and food. Our results show that common buzzards more frequently occupy territories with low IG predation threat, and with no interspecific competitors. Furthermore, common buzzards avoided territories with high levels of grouse, the main food of goshawks, possibly due to a risk of IG predation since grouse can attract goshawks. High levels of small rodents attracted interspecific competitors to common buzzard territories and created a situation where the food was abundant for the common buzzard but so were the competitors. These results suggest interplay between top-down and bottom-up processes influencing interactions between avian predator species. In conclusion, the common buzzard needs to balance the risks of IG predation and interference competition with the availability of its own resources. Presence of other predators associated with high food levels may impede a subordinate predator taking full advantage of the available food. Interspecific interactions with dominant predators have thus the potential to influence the distribution pattern of subordinate predators.

55 Key-words: bird-of-prey; predator avoidance; interference competition; dominance; food conflict 
59 Predation and competition are two major types of interspecific interactions that modify the 60 structure of biological communities (Schoener 1983; Sih et al. 1985; Gurevitch et al. 2000).

61 Predation is a well-known asymmetric interaction because predators gain benefit from their 62 prey (Begon et al. 2005). Similarly, it is common for one species to be affected more than the 63 other in interspecific competition over shared resources (Schoener 1983). The combination of 64 competition and predation, known as intraguild predation (IGP; predation and consumption of competitors of the same guild), has complex impacts on the interacting species, since both species use the same resource(s) while one or both species can also predate the other (Polis et

67 al. 1989).

Predators regulate or limit the abundance and distribution of their prey both directly, by killing them, and indirectly, through non-lethal fear effects, which affect the behaviour and distribution of prey (Sih et al. 1985; Preisser et al. 2005; Cresswell 2008; Ritchie and Johnson 2009). Non-lethal fear effects can cause a prey to avoid areas where the probability to encounter predators is high (Pearson and Livezey 2003; Sergio et al. 2003, 2007; Morosinotto et al. 2010). Prey may also reduce their activities (vocalization, movements) to avoid detection (Crozier et al. 2006; Sergio and Hiraldo 2008), or even move to other areas due to predation threats (Kostrzewa 1991; Chakarov and Krüger 2010). Because of fear effects, prey have less time for foraging and reproduction, which implies that predators impact directly and indirectly the fitness of their prey (Sih et al. 1985; Polis et al. 1989; Ritchie and Johnson 2009). IGP potentially has more complex consequences for the interacting parties than competition or predation alone (Polis et al. 1989; Polis and Holt 1992), because despite the IGP fear, IG prey are often attracted to the same resources as the IG predator. 
81 IGP is a widespread, size-mediated phenomenon (Arim and Marquet 2004), often associated with periods when the principal food of the IG predator is scarce (Polis et al. 1989; Palomares and Caro 1999; Rutz and Bijlsma 2006; Sergio and Hiraldo 2008; Ritchie and Johnson 2009; Greenville et al. 2014). IGP is widely documented among birds-of-prey (Sergio and Hiraldo 2008), many of which are opportunistic feeders and have a broad diet that also includes other raptors, especially during shortage of food (Rutz and Bijlsma 2006; Sergio and Hiraldo 2008). Birds-of-prey involved in IGP need to have a shared resource such as a nesting site (Kostrzewa 1991; Zuberogoitia et al. 2005), breeding territory, i.e. a defended area around a nesting site in a suitable habitat (Krüger 2002a, 2004), diet (Hakkarainen and Korpimäki 1996; Sergio et al. 2007), or a combination of these factors (Poole and Bromley 1988; Fielding et al. 2003). The amount of species-specific resources regulates both species separately, which in turn influences their interaction (Daugherty et al. 2007; Ritchie and Johnson 2009). IGP is most evident among raptor species with similar resource requirements (Korpimäki 1986; Fielding et al. 2003; Martínez et al. 2008). The intensity of IGP can also vary with environmental conditions, such as fragmentation, influencing both species (Møller et al. 2012). Thus, as predator-prey systems, IGP systems are influenced by top-down (effects of IG predator on IG prey) and bottom-up processes (e.g. effects of resources; Ritchie and Johnson 2009; Chakarov and Krüger 2010).

The occurrence of IGP in birds-of-prey is most often determined from observed IGP events or prey items collected from nesting sites (e.g. Mikkola 1976; Pokrovsky and Lecomte 2010).

100 However, a detailed understanding of IGP and its effects on IG prey often requires long-term 101 datasets or field experiments (as e.g. in Kostrzewa 1991; Krüger 2002a; Zuberogoitia et al. 102 2008). Few raptor studies have focused on how IGP and resource levels simultaneously affect IG prey (Krüger 2004; Møller et al. 2012). 
104 Here, we address the impact of an IG predator on an IG prey with two similar-sized forest hawks, the northern goshawk Accipiter gentilis (hereafter goshawk) and the common buzzard Buteo buteo. These species coexist in Eurasia (Cramp and Simmons 1980) where they can

107 compete for nesting sites and territories (Kostrzewa 1991; Krüger 2002a). The dominant 108 goshawk can take over common buzzard nests and may exclude it from high quality forests 109 suitable for both species (Krüger 2002a, 2002b; Hakkarainen et al. 2004). Goshawks can also 110 predate both adult and juvenile common buzzards (eight verified or suspected events recorded

111 in Finland 1981-2009; unpublished common buzzard nest card data of the Finnish Museum of

112 Natural History Luomus), while the common buzzard is not known to predate goshawks

113 (Kostrzewa 1991; Krüger et al. 2001). Both species have declined in Northern Europe, 114 probably due to intensive forestry (Widén 1997). The common buzzard, whose population 115 decline has been steeper than that of the goshawk, is currently listed as threatened in Finland 116 (Mikkola-Roos et al. 2010; Valkama et al. 2011). Additionally, other birds-of-prey breed in 117 hawk nests. Among these, the Ural owl Strix uralensis and the great grey owl S. nebulosa also 118 eat voles, a shared food resource with common buzzards (Korpimäki 1986; Reif et al. 2001),

119 and can compete for nests and food with the common buzzard. Such interspecific competitors were recently called "parallel impacts" that, unlike top-down and bottom-up processes, influence species of the same trophic level (Laundré et al. 2014).

122 We studied the impact of the goshawk IGP threat on common buzzard reproduction in a novel 123 way, by also accounting for other potential factors that can affect their interaction. Our aim was 124 to elucidate how IGP threat posed by the goshawk (top-down factor), interspecific competitors (parallel), and climatic factors as well as food availability (bottom-up factors) affect the occurrence and breeding of the subordinate IG prey, the common buzzard. We used a unique

127 dataset, consisting of comprehensive long-term spatial data on hawk nests, food abundances 128 and climate from North Karelia, Finland. Based on previous evidence, we hypothesized that 
129 (1) due to high risk of IGP, the common buzzard avoids settling close to the goshawk, and this

130 effect can be stronger when the availability of food for the goshawk is low; and (2) the presence

131 of other nest and food competitor species interfere with common buzzard reproduction.

133 Materials and methods

135 Study area

136 This study was carried out in North Karelia, a region of $21584 \mathrm{~km}^{2}$ in eastern Finland (Fig. 1a,

137 b). Land area is dominated by forestry land (89\%) in this region (Ylitalo 2013; Tike 2014).

138 Forests are dominated by Scots pine Pinus sylvestris and Norwegian spruce Picea abies 139 (Ylitalo 2013).

140

141 Study species

142 The goshawk and common buzzard are middle-sized forest-dwelling hawks. Throughout

143 Europe, mature forests and food availability are important for the goshawk (Penteriani 2002;

144 Tornberg et al. 2006; Selås et al. 2008), while food, climate and interspecific interactions

145 regulate common buzzard populations (Sidorovich et al. 2008; Lehikoinen et al. 2009;

146 Chakarov and Krüger 2010; Jonker et al. 2014). Both the goshawk and common buzzard

147 construct their stick nests under the tree crown layer (Penteriani 2002; Lõhmus 2006), and they

148 can breed in each other's nests or in nests built by the European honey-buzzard Pernis apivorus

149 (hereafter honey-buzzard; Online Resource 1). On the other hand, nests of these three hawks 

are also used by other species such as the great grey owl, the Ural owl and the common raven Corvus corax.

152 In Finland, adult goshawks are sedentary while common buzzards are short- or long-distance 153 migrants arriving in Finland in March or April (Saurola et al. 2013). The goshawk feeds mainly 154 on forest grouse, especially the Eurasian black grouse Lyrurus tetrix, and the hazel grouse Bonasa bonasia (Tornberg 2001; Sulkava et al. 2006). Goshawks switch to prey on grouse when they are abundant, and grouse availability affects the population size and dispersal of goshawks (Lindén and Wikman 1983; Byholm et al. 2003; Sulkava et al. 2006). Goshawks predate also corvids Corvidae, trushes Turdus sp., common woodpigeons Columba palumbus,

159 European red squirrels Sciurus vulgaris and occasionally other raptors, including common buzzards (Kostrzewa 1991; Sulkava et al. 2006; Luomus, unpublished raptor nest card data).

161 Common buzzards feed mainly on small mammals (voles of the genus Microtus, water voles Arvicola amphibius and shrews, e.g. Sorex araneus) while grouse chicks and juveniles, other

163 birds, adders Vipera berus, and juveniles of the mountain Lepus timidus and brown hare $L$. europaeus are important alternative food (Reif et al. 2001).

167 The North Karelian Ornithological Society has recorded a history of known hawk territories since the 1980s. For this study, we used this hawk-territory data from 1997-2009. Here, we defined a territory as an ensemble of alternative nests that are assumed to belong to the same hawk pair due to their proximity. Overall, 539 hawk territories were considered, which

171 included between one and seven alternative nests (mean 1.9 nests). For details on territory

172 visits, see Online Resource 2 and Santangeli et al. (2012). 
173 The coordinates of a territory were acquired, separately for each year, from that nest in which

174 preparations for breeding had advanced furthest (typically the nest with a breeding attempt).

175 Each year, common buzzards could choose an alternative nest within their territory that was

176 most distant from the closest occupied goshawk nest (goshawks can also switch between

177 alternative nests in their territory). Thus, year-specific coordinates are better at capturing the

178 potential effect of the goshawk on the common buzzard compared to static coordinates (i.e.

179 fixed territory coordinates for all years), because the goshawk threat (see 'goshawk threat

180 index' section) is distance-based and can change yearly. If several alternative nests within a

181 common buzzard territory had the same status (equally decorated or all unoccupied), the

182 average coordinates of these were used as territory coordinates.

183 In a particular year, a species (common buzzard, goshawk, nest competitor species, see

184 'competitor in territory') was considered to occupy a territory if the species had decorated or

185 was breeding in one of the alternative nests, or if full-grown bird(s) or a fledged brood were

186 observed. A territory was considered unoccupied by a species in a particular year, if the species

187 was not observed in the territory, but had occupied the territory in the past. Two species could co-occupy a common buzzard territory in the same year in different alternative nests (Online Resource 1), but usually different species occupied a common buzzard territory in different

190 years. Thus, a territory could be unoccupied by one species, but occupied by another within a

191 year. Our data included 943 events of territory unoccupancy and 682 events of territory 192 occupancy by common buzzards (events when a territory was unoccupied or occupied by 193 common buzzards in a year) in a total of 378 territories (Fig. 1b).

194 A common buzzard breeding attempt was accounted for in a territory if one of the alternative nests had eggs or chicks (or their remains), or if a fledged brood was observed. Breeding

196 success was defined for those territories that had a breeding attempt with a verified breeding

197 result. A breeding attempt was considered successful if at least one chick was raised at 
198 minimum to ringing age (14-28 days old), otherwise it was deemed unsuccessful. In our study,

199 the common buzzard had 315 successful and 61 unsuccessful breeding attempts for 207

200 territories.

201 The search effort for new hawk territories increased in the 2000s in North Karelia. This led to

202 an increase in the number of hawk territories reported and occupied (Online Resource 3 Fig.

203 1a). This also led to an increased proportion of occupied territories (Online Resource 3 Fig.

204 1b), which was partly due to the fact that occupied territories are more easily found (the

205 occupancy rate of newly found territories was on average 80\%). The yearly occupancy rate in

206 old territories (on average 34\%) increased as well. These changes were therefore taken into

207 account when analysing the data (see below). There were no trends in the proportion of successful breeding attempts (Online Resource 3 Fig. 1b).

210 Goshawk threat index

211 Data were gathered on 551 events of goshawk occupancy from 192 territories during 1997-

212 2009. Goshawk threat surfaces were constructed across the study region for each year based

213 on the location of occupied goshawk territories. The goshawk threat index ranged from 0 to 1

214 and was highest in occupied goshawk territories. Goshawk threat was assumed to follow a flat-

215 top bivariate Gaussian kernel around a goshawk territory. We used a flat-top kernel because

216 real threat sensed by common buzzards in the proximity of goshawks is not known and

217 therefore, we assumed it constant and maximal within a certain range around occupied

218 goshawk territories (see Online Resource 2). Since the behaviour of breeding goshawks is not

219 well known, nine different goshawk threat surfaces were constructed using all combinations of

220 three flat-top ranges (1, 2 and $3 \mathrm{~km})$ and standard deviations $(\mathrm{SD}=1,3$ and $4 \mathrm{~km})$ as explained 
221 in Online Resource 2. The goshawk threat surfaces differed based on how far the maximum threat $(=1)$ was assumed to extend around an occupied goshawk territory (controlled with the flat-top range distance), and how fast the threat decreased towards zero beyond that distance (regulated with SD). Each common buzzard territory then received the associated nine different goshawk threat indices from the nine goshawk threat surfaces based on the goshawk threat value on the surface at the common buzzard territory coordinates. The threat indices varied annually among common buzzard territories because they depended on how far the common buzzard and goshawk territories were from each other in each year.

An increase in search effort had a positive impact on the goshawk threat index (Online Resource 3 Fig. 2) because new goshawk and common buzzard territories were found between previously known territories. This was shown by decreases in inter- and intraspecific nearestneighbour distances (Online Resource 3 Figs. 3a-c). Therefore, nine residual goshawk threat indices were calculated from which the impact of increased search effort was removed. These were obtained by fitting linear models with one of the nine goshawk threat indices in a common buzzard territory as a response, and a measure of effort (total number of reported goshawk, common buzzard and honey-buzzard territories in each year) as an explanatory variable (Online Resource 3 Fig. 1a). All three hawk species were considered, because they frequently use each other's nests and new common buzzard territories could have been previously occupied by the goshawk or the honey-buzzard. The residuals of the nine models were then used as an effort-corrected goshawk threat in the analyses (hereafter goshawk threat).

243 The great grey owl, Ural owl and common raven also occupied alternative nests in common 244 buzzard territories during the study years (in 49, 10 and one occasion, respectively) and were 
considered as interspecific competitors in common buzzard territories. These species occupied a nest before the common buzzards arrived from migration, making those nests unavailable to common buzzards. The great grey owl and Ural owl are vole specialists (Korpimäki 1986; Voous 1988) and may compete for food, or hunting patches, with common buzzards. Of the other nest users, the honey-buzzard was not considered a competitor for the common buzzard because honey-buzzards generally migrate 3-4 weeks after the common buzzards. The goshawk's influence on the common buzzard was measured using goshawk threat as defined in the previous section. For further details on interspecific occupiers of common buzzard territories, see Online Resource 1.

To examine if the presence of a competitor species in a territory affected the occupancy or reproduction of the common buzzard, a 'competitor in territory' variable was defined as 1 , if the owls or the common raven occupied the territory, and 0 , if no competitors were reported to occupy the territory within a year. Competitors at least in one year were found in 48 territories, whereas competitors were absent from 330 territories throughout the study period.

Vole index

261 The Finnish Forest Research Institute (currently Natural Resources Institute Finland) gathered

262 data on vole abundance (the main food of common buzzards) from four trapping sites (black

263 squares in Fig. 1b). In the spring of each year, voles were trapped in forest and open grassland 264 habitats within the trapping sites (Korpela et al. 2013). The abundance of the two most common vole species, the field vole Microtus agrestis and the bank vole Myodes glareolus, were pooled annually from the two habitats at each trapping site. Populations of these species are geographically synchronous (Korpela et al. 2013). A vole abundance index was calculated for 
each trapping site using the formula: $\log _{\mathrm{e}}\left((\right.$ pooled number of voles +1$)$ trap nights $\left.{ }^{-1}\right) \times 100$.

269 The vole index was standardized to mean $=0$ and $\mathrm{SD}=1$ for each trapping site; this standardization corrects for variation in habitat quality between trapping sites. A yearly average

271 of the standardized vole indices across the different trapping sites was then calculated. Vole

272 abundance fluctuated widely in eastern Finland (Online Resource 3 Fig. 4).

274 Grouse data

275 Grouse abundance was used as a measure of food levels for goshawks (main food) and common

276 buzzards (alternative food). Grouse abundance (individuals forest- $\mathrm{km}^{-2}$ of the black grouse, hazel grouse, capercaillie Tetrao urogallus and willow grouse Lagopus lagopus) was estimated using wildlife triangle surveys from 1996 to 2009 (Lindén et al. 1996; details in Online Resource 2). Data were gathered yearly from an average of 133 (range $=121-150$ ) wildlife

280 triangles. All individuals regardless of the species were pooled to create a grouseall-index, and 281 all juveniles were used to create a grouse ${ }_{j u v}$-index for each wildlife triangle (Online Resource 282 2).

283 To generalise grouse abundances from wildlife triangles to the whole study area, an 284 interpolation map was constructed for the grouse ${ }_{a 11}$ - and grouse ${ }_{j u v}$-indices for each year using 285 the inverse distance weight method (IDW; see Online Resource 2) in ArcGIS 10 (Esri, USA).

286 An interpolated value of grouse all- $^{-}$and grouse $_{j u v}$-index was then extracted at each common buzzard territory location for each year (Online Resource 2).

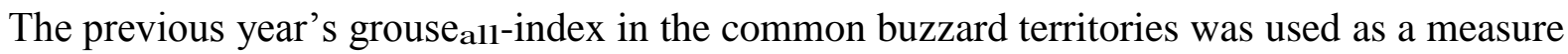
of food abundance for local overwintering goshawks because it was assumed that goshawks potentially prefer and overwinter successfully in areas with abundant grouse. The current year's 


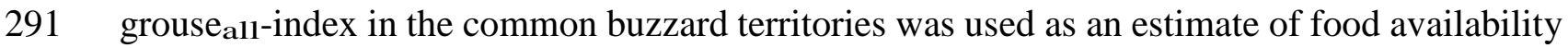

292 for the goshawk during the breeding season, and the current year's grouse ${ }_{j u v}$-index was used

293 as a measure of alternative food for the common buzzard.

295 Weather data

296 Spring and early summer temperatures, as well as early summer precipitation affect the onset

297 of breeding and breeding performance of the common buzzard in Finland (Lehikoinen et al.

298 2009). Therefore, March, April and June mean temperatures and June precipitation were

299 included in our analyses.

300 Weather data included daily precipitation and averages of daily temperatures within each $10 \times$

301 10-km grid-cell of the study region (Venäläinen et al. 2005). Monthly mean temperatures and

302 total precipitation were then calculated and used for the common buzzard territories in the

303 respective grid-cells.

306 Generalized linear mixed models (GLMMs; Zuur et al. 2009) were used to independently

307 model the territory occupancy $(1=$ occupied, $0=$ unoccupied $)$ and breeding success in a 308 territory $(1=$ successful, $0=$ unsuccessful $)$ of the common buzzard. Both models assumed a

309 binomial distribution and were modelled using a logit-link function. Because our data was

310 partly gathered from the same territories but for different years, the territory identity was used

311 as a random effect on the intercept in all models to avoid pseudoreplication (Hurlbert 1984).

312 Because the inference made from territories visited more often was considered more reliable, 
313 territories which were visited multiple times were given double the weights of the territories

314 visited only once. Model variables were standardized to mean $=0$ and $\mathrm{SD}=0.5$ to render the

315 variables (including binomial variables) comparable with each other (Gelman 2008). The

316 residuals of the models were tested using a Moran's $I$ test to verify the absence of spatial

317 autocorrelation (Bivand 2014). All GLMM-analyses were conducted using the package lme4

318 (Bates et al. 2014) within the R statistical language (R Core Team 2013).

319 Territory occupancy

320 The nine different goshawk threats were first fitted to nine GLMMs to test how each goshawk

321 threat influence common buzzard occupancy or breeding success. Akaike information criterion

322 (AIC) was used to select the GLMM, and thus goshawk threat, that most parsimoniously explained the occupancy or breeding success of the common buzzard (Zuur et al. 2009). If different alternative models yielded an AIC within $\leq 2$ of the best model (Burnham and Anderson 2002; Grueber et al. 2011), the subsequent occupancy or breeding success analyses were also conducted with these goshawk threats to see whether their information was congruent with the model including the best threat index.

328 For common buzzard territory occupancy, the influences of the vole index, the goshawk threat, the previous year's grouse all-index, competitor in territory, and March and April temperatures were considered. Also the interaction between the goshawk threat and the previous year's grouse all-index was examined to test whether the influence of goshawk threat on common buzzard occupancy depended on the main food level of the goshawk.

333 Since the search effort and consequently the proportion of occupied common buzzard 334 territories increased during the studied years, the effects on occupancy of newly found 335 territories and the sampling year were tested. The best occupancy model was thus refined by 336 (i) excluding the first-year data from new territories (which are often occupied when found), 
or (ii) excluding the first-year data from new territories and including a continuous variable

338 'year' to the model. These refinements accounted for the impact of an increase in sampling effort on occupancy (i) due to new territories only, and (ii) in old territories. Additionally,

340 common buzzard territory occupancy in the previous year may partly explain the occupancy

341 probability in the next year because territories can tend to be re-occupied in succeeding years.

342 This was tested by (iii) adding to the final occupancy model a binomial variable "previous occupancy', which defined whether a territory was occupied or not by the common buzzard in

344 the previous year. The first-year data was excluded from new territories before this refinement

345 because no information on the previous occupancy was available for the first year.

346 Additionally, since most of the interspecific competitors were vole-eating owls, the effect of vole abundance on occupancy of competitors in common buzzard territories was studied using only the 48 territories where a competitor was found at least once during the sampling period.

Data were included from all years from these territories, and a binomial-GLMM was then fitted where the presence or absence of competitors in these territories was explained by the vole 351 index.

Breeding success

The influences of the following variables on common buzzard breeding success were considered: the vole index, the goshawk threat, the current year's grouse all-index, the current year's grouse ${ }_{j u v}$-index, April and June temperatures, and June precipitation. However, the two grouse indices were highly correlated $(|r|>0.7$; Dormann et al. 2013). Therefore, their influences on breeding success were studied independently with GLMMs whose AICs were then compared. The GLMM with the grouse all-index had a lower AIC than the GLMM with

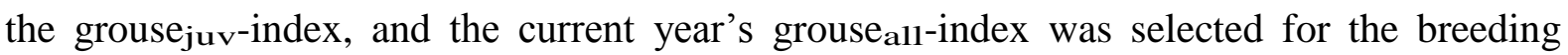
success analysis. An interaction between the goshawk threat and the current year's grouse al1- 
361 index was included to examine the impact of the goshawk threat on breeding success when the main food level of the goshawk varied. The variable 'competitor in territory' was excluded from the breeding success analyses because common buzzards rarely bred in territories where competitors were present (only five breeding attempts in territories with competitors, as opposed to 371 breeding attempts without a competitor in the territory).

\section{Results}

\section{Territory occupancy}

370 The occupancy of common buzzard territories was most influenced by goshawk threat with a

371 1-km range and SD 1 (Online Resource 4). The probability of common buzzard occupancy

372 increased with decreasing goshawk threat (Fig. 2), lower grouseal1-levels in the previous year,

373 lower March temperatures and when a competitor was not found in the territory (Table 1). The

374 vole index, April temperatures and the interaction of the goshawk threat and previous-year's

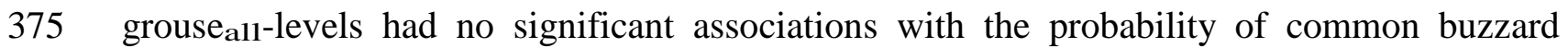
occupancy, and the interaction was removed from the final model presented in Table 1.

377 When we run the final occupancy model (i) without the first-year data of new territories, or (ii)

378 as in (i) but with year as a continuous explanatory variable, or (iii) as in (i) but with a 'previous

379 occupancy' as an explanatory variable, the results were consistent with those presented in Table

380 1. The 'year' variable (ii) was not significantly associated with territory occupancy in the old

381 territories. However, 'previous occupancy' (iii) had a significant and positive association with 
territory occupancy (estimate: 0.53 , SE: $0.11, z: 4.64, P<0.001$ ). Thus, common buzzards occupied more likely territories that the species had occupied in the previous year.

384 The probability of presence of a 'competitor in territory' was significantly higher with a higher vole index in those common buzzard territories from which a competitor species had been reported at least in one year (estimate: 1.52, SE: 0.32, z: 4.72, $P<0.001$; Online Resource 3 Fig. 5). This means that the presence of vole-eating competitors, mainly Strix owls, in common buzzard territories was dependent on vole-levels.

Despite the overall avoidance of the IG predator goshawk, some common buzzards settled in goshawk territories and shared a territory with goshawks during the same year in 27 occasions.

391 Moreover, common buzzards usually occupied abandoned goshawk territories when vacant (Online Resource 1). Instead, presence of interspecific competitors interfered with the common buzzards. Only in a few occasions did the common buzzard re-occupy their territory where a competitor had settled (Online Resource 1).

397 The probability of successful breeding of the common buzzard was higher with increasing 398 April temperatures, the only significant variable in the model (Table 2). The interaction of the 399 selected goshawk threat (with a 1-km range and SD 1, Online Resource 4) and the current 400 year's grouse all-index was not significantly associated with breeding success, and we removed 401 it from the final model. Models with the eight other goshawk threats yielded almost similar 402 AIC values with the model containing the selected threat index (Online Resource 4), and the 403 subsequent breeding success analyses with these alternative goshawk threats gave congruent 
404 results with those in Table 2. The goshawk threat was not significantly associated with common 405 buzzard breeding success in any of the models.

406 Of the 61 breeding failures, 47 occurred during the egg-laying or incubation period in April407 May, while 14 occurred at the nestling period.

408 Common buzzards managed to breed successfully in the same territory with the IG predator 409 goshawk in 15 occasions, but rarely with owl-competitors (only twice with the great grey owl, 410 Online Resource 1).

\section{Discussion}

413 Our results indicate that avoidance of both intraguild predators and interspecific competitors

414 affect the settlement of common buzzards in a territory. Both higher goshawk threat and

415 presence of interspecific competitors in the territory decreased the probability of common 416 buzzard occupancy. This suggests that presence of IG predators or competitors are important 417 clues for common buzzards arriving from migration, when they decide whether to settle in a 418 territory to breed. After common buzzards minimized the levels of these interferences and 419 chose to occupy a safe territory (often with low goshawk threat and no interspecific 420 competitors), the remaining level of goshawk threat had no significant impact on common 421 buzzard breeding success. Thus, factors determining the settling decision of common buzzards 422 no longer seem to affect their breeding performance.

423 Additionally, late-winter temperatures affected common buzzard territory occupancy because 424 the occupancy probability increased with low March temperatures. Cold and snowy winters 425 have sometimes been associated with better vole survival (Aars and Ims 2002). However, 
426 because vole levels had no significant impact on common buzzard occupancy, there is no clear evidence of the underlying mechanism that made March temperatures influence occupancy.

428 Common buzzard breeding success increased with higher April temperatures. Egg-laying 429 normally occurs in late April, but common buzzards breed earlier in warm springs (Kontkanen 430 and Nevalainen 2002; Lehikoinen et al. 2009). Warm spring temperatures seem beneficial 431 during the sensitive early stage of common buzzard breeding, when breeding attempts can be vulnerable for adverse cold spells. Most breeding failures occurred during the egg-laying and incubation periods, although some late failures may have been missed because nests were not 434 always visited after ringing.

435 We found no significant impact of vole levels on common buzzard occupancy or breeding success. These results seem to contradict the idea that voles are important prey for common buzzards. However, it is possible that our vole index captured only coarse scale patterns and as such did not reveal an association with common buzzard territory occupancy and breeding success. Due to few vole trapping sites, vole data were year-specific and not territory-specific

440 within a year. Thus, if locally high vole numbers increased occupancy or breeding success in 441 some territories, this effect was missed. Another possibility is that voles had no significant 442 effect on common buzzard occupancy or breeding success, because common buzzards can 443 predate other prey, such as birds, when voles are scarce (Reif et al. 2001). Also appearance of 444 interspecific competitors, associated with vole peak years, could reduce the significance of vole 445 abundance to common buzzards by suppressing common buzzard occupancy in those years. It 446 is also possible that avoidance of the IG predator (goshawk) is more important for the common 447 buzzard, and it could thus mask the importance of vole abundance. 
450 We found no support for the hypothesis that the effect of IGP threat on common buzzard 451 occupancy would be higher when the main food level of the IG predator is low. Instead, the 452 overall negative effect of goshawk threat on common buzzard occupancy indicated that 453 subordinate common buzzards generally avoid territories with a high risk of IGP, irrespective of levels of the main food of the IG predator. This fear of IGP is probably adaptive, since the offspring of subordinate predators are occasionally predated by goshawks (Petty et al. 2003; Bijlsma 2004). Common buzzard chicks are vulnerable in their open nest and opportunistically hunting goshawks can attack common buzzard nests irrespective of grouse abundance. The goshawk threat that most affected common buzzard occupancy had a range of 1-km and SD 1. This range corresponds to the average foraging distance of goshawks in a Scandinavian preyrich environment (Penteriani et al. 2013).

It is plausible that the frequent activity of foraging goshawks would overly stress the common buzzards and therefore, the territories with a high goshawk threat often remained unoccupied by buzzards. However, it is important to recall that the goshawk threat index does not translate into a direct IGP risk, in the sense that common buzzards would always be predated from territories with a high risk, as discussed below. Nevertheless, Sergio and Hiraldo (2008) concluded that even rare IGP-events are enough to sustain IGP-fear in the IG prey population,

467 and the fear of IGP triggers behavioural changes, such as predator avoidance. The presence of 468 IG predators can lead to territory abandonments and decreasing occupancy rates of the IG prey 469 (Sergio and Hiraldo 2008). IG predators can even impact the diversity of the whole raptor assemblage by their control over lower-level predators (Sergio et al. 2007). In line with these

471 previous findings, we found that common buzzard occupancy was lower with increasing threat 472 of the IG predator. 
473 Despite the potential IGP threat, some common buzzards settled and bred in goshawk 474 territories. This reflects the contradiction in IGP when the IG prey is attracted to the same 475 resources shared with its IG predator. Common buzzards and goshawks use similar forests for 476 nesting (Lõhmus 2006), although their forest habitat use may differ otherwise, and both can

477 benefit from already existing nests (Kostrzewa 1991; Jiménez-Franco et al. 2014). Common 478 buzzards that are bold, or oblivious, enough to breed in the same territory with goshawks may 479 even benefit from protection from the latter against other nest predators, such as corvids, and 480 interspecific competitors, such as Ural owls, that avoid goshawks (Krüger 2002a; Pakkala et 481 al. 2006; Rebollo et al. 2011). Subordinate species may also show individual plasticity by being 482 bolder or becoming more experienced in defending their nesting sites (Krüger 2002a; van 483 Lanen et al. 2011).

486 Common buzzard occupancy was lower in territories where competitors were present. In 487 addition, common buzzards rarely bred successfully with competitors in the same territory (Online Resource 1). Great grey owls and Ural owls eat mainly small rodents and they are not known to predate common buzzards (Korpimäki 1986; Voous 1988). However, since these owls compete for both nests and food with the common buzzard, such an intensive interspecific competition likely affects common buzzards. Ural owls and great grey owls are also known to aggressively defend their nests (Voous 1988), which can result in frequent conflicts with interspecific competitors and unsuccessful breeding of both competitors (Kostrzewa 1991).

494 While some common buzzard individuals succeed in defending their territories against 495 interspecifics (Kostrzewa 1991), it would be overall more advantageous for the common 496 buzzards to avoid breeding near competitors. 
498 Food conflict

499 Common buzzard occupancy probability decreased with increasing levels of grouse in the

500 previous year. High levels of grouse in the landscape may translate into a higher risk of IGP

501 for the common buzzard because grouse can attract goshawks. Similarly, an abundance of voles

502 could enhance interference with interspecific raptors since the presence of vole-eating

503 predators in common buzzard territories was associated with high vole levels. Common

504 buzzards arriving from migration have to make a rapid decision on occupancy based on all

505 information from surroundings since the time between the arrival, territory establishment and

506 the onset of breeding is short (Kontkanen and Nevalainen 2002). This stage is crucial because

507 a breeding failure due to bad occupancy decision would entail a waste of reproductive

508 investment. Therefore, although abundant food would appear to be beneficial for the common

509 buzzards, they might in reality prefer to avoid areas with high levels of grouse or voles, due to

510 increased risk of IGP or interspecific competition.

511 Thus, although voles are the main food and grouse are an alternative food for the common

512 buzzards, interspecific competitors or IG predators can prevent common buzzards from fully

513 exploiting the peak phases of these food resources. Such a trade-off between exploitation of

514 food abundance and avoidance of IG predators or food competitors was previously suggested

515 for birds-of-prey by Potapov (1997). In his study area, rough-legged buzzards Buteo lagopus

516 were not the most abundant during a lemming peak year. The likely reason was that a bigger

517 predator, the nomadic snowy owl Bubo scandiacus, bred then in larger numbers than usually.

518 A similar trade-off between food availability and predation risk was also suggested by Heithaus

519 and Dill (2002) for marine ecosystem, where bottlenose dolphins (Tursiops aduncus) avoided 
520 foraging in food-rich shallow waters due to high predation risk by tiger sharks (Galeocerdo cuvier).

523 Top-down, bottom-up and parallel effects

524 The relative importance and interplay of top-down and bottom-up processes in regulating 525 populations is a focal but controversial issue for terrestrial, freshwater and marine ecosystems 526 (Jeppesen et al. 1997; Pace et al. 1999; Baum and Worm 2009; Greenville et al. 2014; Laundré 527 et al. 2014). Predation and competition can have large effects on communities, and predation 528 effects may partly depend on the intensity of intra- and interspecific competition (Sih et al. 1985). In our study, we found evidence of top-down control (goshawk threat influenced common buzzard occupancy) that was unrelated to main food levels (grouse) of the IG

531 predator. We also detected bottom-up effects on the common buzzard, because grouse levels 532 negatively affected occupancy. These findings are in line with those of Thompson and Gese 533 (2007) based on an IGP system of coyotes (Canis latrans, the IG predator) and swift foxes 534 (Vulpes velox, the IG prey), whereby swift foxes select sites based on safety from IG predators rather than resource availability.

536 We also found parallel impacts (i.e. presence of interspecific competitors that reduce common 537 buzzard occupancy) and indirect bottom-up effects whereby high resource levels (voles) 538 attracted interspecific competitors that in turn interfered (as parallel effects) with the common buzzard. This corresponds to a theoretical situation where a dominant interspecific competitor confounds bottom-up effects on a subordinate competitor (Laundré et al. 2014).

541 Overall it seems that both IG predators and interspecific competitors can impact the behaviour 542 (occupancy) of subordinate species in a "landscape of fear", restricting areas of suitable safe 
543 habitat for subordinate species (Chakarov and Krüger 2010; Laundré et al. 2014). In our study

544 area, interspecific competitors were rather rare (appearing in 48 out of 330 common buzzard

545 territories) and may not have a major impact on the threatened common buzzard. However, in

546 areas where interspecific predators and competitors are abundant, they can have implications

547 on conservation of subordinate predators (Buchanan et al. 2007).

\section{Conclusions}

550 We have shown that interspecific interactions with an intraguild predator and other competitors

551 appear to be important in determining the occupancy decisions of a subordinate predator early

552 in the breeding season, before a substantial investment in reproduction is made. Common

553 buzzard occupancy was driven by the avoidance of an IG predator (goshawk) and interspecific

554 competitors (Strix owls). Interspecific interactions may even prevent the subordinate predator

555 from fully exploiting the optimal periods of its food resources.

556 Our study shows that interspecific interactions have the potential to shape the distribution 557 patterns of subordinate predators. This can have important implications for species

558 management in changing environments. Specifically, a subordinate species could be excluded owing to predation threat and competition from areas otherwise apparently suitable for 560 breeding.

\section{Acknowledgements}

563 We are grateful for the many volunteer bird-of-prey ringers for their long-term fieldwork. We

564 thank Jukka Rintala for retrieving the grouse data, Henriikka Simola and Kaisa Välimäki for providing the weather data, and Sanna Mäkeläinen for geoprocessing advice. We also want to 
acknowledge Sara Fraixedas and two anonymous reviewers for their comments that improved

567 the manuscript. This study was supported by the Finnish Museum of Natural History Luomus.

568 HB received funding from the Kone Foundation, the University of Helsinki, the Doctoral

569 Programme in Wildlife Biology Research Luova of the University of Helsinki, and the Finnish

570 Museum of Natural History Luomus. TL received funding from the Academy of Finland.

572 Conflict of Interest: The authors declare that they have no conflict of interest.

573 Ethical approval: All applicable institutional and/or national guidelines for the care and use 574 of animals were followed.

\section{$576 \quad$ References}

578 Aars J, Ims RA (2002) Intrinsic and climatic determinants of population demography: The

579 winter dynamics of tundra voles. Ecology 83:3449-3456 doi: http://dx.doi.org/10.1890/00129658(2002)083[3449:IACDOP]2.0.CO;2

581 Arim M, Marquet PA (2004) Intraguild predation: A widespread interaction related to species

582 biology. Ecol Lett 7:557-564 doi: 10.1111/j.1461-0248.2004.00613.x

583 Bates D, Maechler M, Bolker B, Walker S (2014) Package 'Ime4'. Linear mixed-effects 584 models using Eigen and S4, version 1.0-6

585 Baum JK, Worm B (2009) Cascading top-down effects of changing oceanic predator

586 abundances. J Anim Ecol 78:699-714 doi: 10.1111/j.1365-2656.2009.01531.x 
587 Begon M, Townsend CR, Harper JL (2005) Ecology: From individuals to ecosystems, 4 edn. 588 Blackwell, Malden, MA

589 Bijlsma RG (2004) What is the predation risk for European honey buzzards Pernis apivorus

590 in Dutch forests inhabited by food-stressed northern goshawks Accipiter gentilis? De

591 Takkeling 12:185-197

592 Bivand R (2014) Package 'spdep'. Spatial dependence: Weighting schemes, statistics and 593 models, version $0.5-71$

594 Buchanan JB, Gutiérrez RJ, Anthony RG, Cullinan T, Diller LV, Forsman ED, Franklin AB 595 (2007) A synopsis of suggested approaches to address potential competitive interactions 596 between barred owls (Strix varia) and spotted owls (S. occidentalis). Biol Invasions 9:679$597 \quad 691$ doi: 10.1007/s10530-006-9068-7

598 Burnham K, Anderson D (2002) Model selection and multimodel inference. A practical 599 information-theoretic approach, 2nd edn. Springer-Verlag, New York

600 Byholm P, Saurola P, Lindén H, Wikman M (2003) Causes of dispersal in northern goshawks 601 (Accipiter gentilis) in Finland. Auk 120:706-716 doi: 10.2307/4090101

602 Chakarov N, Krüger O (2010) Mesopredator release by an emergent superpredator: A natural 603 experiment of predation in a three level guild. PLOS ONE 5:e15229 doi:

604 10.1371/journal.pone.0015229

605 Cramp S, Simmons KEL (1980) Handbook of the birds of Europe, the Middle East and North 606 Africa: The birds of the Western Palearctic, hawks to bustards. Oxford University Press, 607 Oxford 
608 Cresswell W (2008) Non-lethal effects of predation in birds. Ibis 150:3-17 doi:

609 10.1111/j.1474-919X.2007.00793.x

610 Crozier ML, Seamans ME, Gutiérrez RJ, Loschl PJ, Horn RB, Sovern SG, Forsman ED

611 (2006) Does the presence of barred owls suppress the calling behavior of spotted owls?

612 Condor 108:760-769

613 Daugherty MP, Harmon JP, Briggs CJ (2007) Trophic supplements to intraguild predation.

614 Oikos 116:662-677 doi: 10.1111/j.2007.0036-1299.15378.x

615 Dormann CF, Elith J, Bacher S, Buchmann C, Carl G, Carré G, Marquéz JRG, Gruber B, 616 Lafourcade B, Leitão PJ, Münkemüller T, McClean C, Osborne PE, Reineking B, Schröder 617 B, Skidmore AK, Zurell D, Lautenbach S (2013) Collinearity: A review of methods to deal 618 with it and a simulation study evaluating their performance. Ecography 36:027-046 doi: $619 \quad 10.1111 /$ j.1600-0587.2012.07348.x

620 Fielding AH, Haworth PF, Morgan DH, Thompson DBA, Whitfield DP (2003) The impact of 621 golden eagles (Aquila chrysaetos) on a diverse bird of prey assemblage. In: Thompson DBA, 622 Redpath SM, Fielding AH, Marquiss M and Galbraith CA (eds) Birds of prey in a changing 623 environment. The Stationary Office, Edinburgh, pp 221-243

624 Gelman A (2008) Scaling regression inputs by dividing by two standard deviations. Stat Med $625 \quad 27: 2865-2873$ doi: 10.1002/sim.3107

626 Greenville AC, Wardle GM, Tamayo B, Dickman CR (2014) Bottom-up and top-down

627 processes interact to modify intraguild interactions in resource-pulse environments.

628 Oecologia 175:1349-1358 doi: 10.1007/s00442-014-2977-8 
629 Grueber CE, Nakagawa S, Laws RJ, Jamieson IG (2011) Multimodel inference in ecology

630 and evolution: Challenges and solutions. J Evol Biol 24:699-711 doi: 10.1111/j.1420-

$6319101.2010 .02210 . x$

632 Gurevitch J, Morrison JA, Hedges LV (2000) The interaction between competition and

633 predation: A meta-analysis of field experiments. Am Nat 155:435-453 doi: 10.1086/303337

634 Hakkarainen H, Mykrä S, Kurki S, Tornberg R, Jungell S (2004) Competitive interactions

635 among raptors in boreal forests. Oecologia 141:420-424 doi: 10.1007/s00442-004-1656-6

636 Hakkarainen H, Korpimäki E (1996) Competitive and predatory interactions among raptors:

637 An observational and experimental study. Ecology 77:1134-1142 doi: 10.2307/2265582

638 Heithaus MR, Dill LM (2002) Food availability and tiger shark predation risk influence

639 bottlenose dolphin habitat use. Ecology 83:480-491 doi: 10.2307/2680029

640 Hurlbert SH (1984) Pseudoreplication and the design of ecological field experiments. Ecol

641 Monogr 54:187-211 doi: http://dx.doi.org/10.2307/1942661

642 Jeppesen E, Jensen JP, Søndergaard M, Lauridsen T, Pedersen LJ, Jensen L (1997) Top-down

643 control in freshwater lakes: The role of nutrient state, submerged macrophytes and water

644 depth. Hydrobiologia, 342-343, 151-164 doi: 10.1023/A:1017046130329

645 Jiménez-Franco MV, Martínez JE, Calvo JF (2014) Patterns of nest reuse in forest raptors

646 and their effects on reproductive output. J Zool 292:64-70 doi: 10.1111/jzo.12085

647 Jonker RM, Chakarov N, Krüger O (2014) Climate change and habitat heterogeneity drive a

648 population increase in common buzzards Buteo buteo through effects on survival. Ibis

649 156:97-106 doi: 10.1111/ibi.12124 
650 Kontkanen H, Nevalainen T eds (2002) Birds of prey and forestry (in Finnish). Siipirikko 29:1-80 Accessible from: www.pklty.fi/eSR/SR-2002-2-PeMe.pdf

652 Korpela K, Delgado M, Henttonen H, Korpimäki E, Koskela E, Ovaskainen O, Pietiäinen H, 653 Sundell J, Yoccoz NG, Huitu O (2013) Nonlinear effects of climate on boreal rodent 654 dynamics: Mild winters do not negate high-amplitude cycles. Global Change Biol 19:697-710 655 doi: $10.1111 / \mathrm{gcb} .12099$

656 Korpimäki E (1986) Niche relationships and life-history tactics of three sympatric Strix owl 657 species in Finland. Ornis Scandinavica 17:126-132 doi: 10.2307/3676861

658 Kostrzewa A (1991) Interspecific interference competition in three European raptor species.

659 Ethology Ecology and Evolution 3:127-143 doi: 10.1080/08927014.1991.9525379

660 Krüger O (2002a) Interactions between common buzzard Buteo buteo and goshawk Accipiter 661 gentilis: Trade-offs revealed by a field experiment. Oikos 96:441-452 doi: 10.1034/j.1600$662 \quad 0706.2002 .960306 . x$

663 Krüger O (2002b) Analysis of nest occupancy and nest reproduction in two sympatric 664 raptors: common buzzard Buteo buteo and goshawk Accipiter gentilis. Ecography 25:523-532 665 doi: 10.1034/j.1600-0587.2002.250502.x

666 Krüger O (2004) The importance of competition, food, habitat, weather and phenotype for the 667 reproduction of buzzard Buteo buteo. Bird Study 51:125-132 doi:

$668 \quad 10.1080 / 00063650409461344$

669 Krüger O, Lindström J, Amos W (2001) Maladaptive mate choice maintained by

670 heterozygote advantage. Evolution 55:1207-1214 Accessible from:

$671 \quad$ www.jstor.org/stable/2680287 
672 Laundré JW, Hernández L, López Medina P, Campanella A, López-Portillo J, González-

673 Romero A, Grajales-Tam KM, Burke AM, Gronemeyer P, Browning DM (2014) The

674 landscape of fear: The missing link to understand top-down and bottom-up controls of prey

675 abundance? Ecology 95:1141-1152 doi: 10.1890/13-1083.1

676 Lehikoinen A, Byholm P, Ranta E, Saurola P, Valkama J, Korpimäki E, Pietiäinen H,

677 Henttonen H (2009) Reproduction of the common buzzard at its northern range margin under

678 climatic change. Oikos 118:829-836 doi: 10.1111/j.1600-0706.2008.17440.x

679 Lindén H, Wikman M (1983) Goshawk predation on tetraonids: Availability of prey and diet 680 of the predator in the breeding season. J Anim Ecol 52:953-968 doi: 10.2307/4466

681 Lindén H, Helle E, Helle P, Wikman M (1996) Wildlife triangle scheme in Finland: Methods 682 and aims for monitoring wildlife populations. Finnish Game Research 49:4-11

683 Lõhmus A (2006) Nest-tree and nest-stand characteristics of forest-dwelling raptors in east684 central Estonia: Implications for forest management and conservation. Proc Estonian Acad 685 Sci Biol Ecol 55:31-50

686 Martínez JE, Martínez JA, Zuberogoitia I, Zabala J, Redpath SM, Calvo JF (2008) The effect 687 of intra- and interspecific interactions on the large-scale distribution of cliff-nesting raptors. 688 Ornis Fenn 85:13-21

689 Mikkola H (1976) Owls killing and killed by other owls and raptors in Europe. British Birds $690 \quad 69: 144-154$

691 Mikkola-Roos M, Tiainen J, Below A, Hario M, Lehikoinen A, Lehikoinen E, Lehtiniemi T, 692 Rajasärkkä A, Valkama J, Väisänen R (2010) Birds. In: Rassi P, Hyvärinen E, Juslén A and 
693 Mannerkoski I (eds) The 2010 Red List of Finnish Species. Ympäristöministeriö \& Suomen 694 ympäristökeskus, Helsinki, pp 320-331

695 Møller AP, Solonen T, Byholm P, Huhta E, Nielsen JT, Tornberg R (2012) Spatial 696 consistency in susceptibility of prey species to predation by two Accipiter hawks. J Avian 697 Biol 43:390-396 doi: 10.1111/j.1600-048X.2012.05723.x

698 Morosinotto C, Thomson RL, Korpimäki E (2010) Habitat selection as an antipredator 699 behaviour in a multi-predator landscape: all enemies are not equal. J Anim Ecol 79:327-333 700 doi: 10.1111/j.1365-2656.2009.01638.x

701 Pace ML, Cole JJ, Carpenter SR, Kitchell JF (1999) Trophic cascades revealed in diverse 702 ecosystems. TREE 14:483-488 doi: 10.1016/S0169-5347(99)01723-1

703 Pakkala T, Kouki J, Tiainen J (2006) Top predator and interference competition modify the

704 occurrence and breeding success of a specialist species in a structurally complex forest

705 environment. Ann Zool Fennici 43:137-164 Accessible from:

706 www.sekj.org/PDF/anzf43/anzf43-137.pdf

707 Palomares F, Caro TM (1999) Interspecific killing among mammalian carnivores. Am Nat $708 \quad$ 153:492-508 doi: 10.1086/303189

709 Pearson RR, Livezey KB (2003) Distribution, numbers and site characteristics of spotted 710 owls and barred owls in the Cascade Mountains of Washington. J Raptor Res 37:265-276

711 Penteriani V (2002) Goshawk nesting habitat in Europe and North America: A review. Ornis

712 Fenn 79:149-163 Accessible from: www.ornisfennica.org/search.htm 
713 Penteriani V, Rutz C, Kenward R (2013) Hunting behaviour and breeding performance of

714 northern goshawks Accipiter gentilis, in relation to resource availability, sex, age and

715 morphology. Naturwissenschaften 100:935-942 doi: 10.1007/s00114-013-1093-7

716 Petty SJ, Anderson DIK, Davison M, Little B, Sherratt TN, Thomas CJ, Lambin X (2003)

717 The decline of common kestrels Falco tinnunculus in a forested area of northern England:

718 The role of predation by northern goshawks Accipiter gentilis. Ibis 145:472-483 doi:

719 10.1046/j.1474-919X.2003.00191.x

720 Pokrovsky I, Lecomte N (2010) Peregrine falcons kill a gyrfalcon feeding on their nestling. J

721 Raptor Res 44:66-69

722 Polis GA, Myers CA, Holt RD (1989) The ecology and evolution of intraguild predation:

723 Potential competitors that eat each other. Annu Rev Ecol Syst 20:297-330 doi:

724 10.1146/annurev.es.20.110189.001501

725 Polis GA, Holt RD (1992) Intraguild predation: The dynamics of complex trophic

726 interactions. Trends Ecol Evol 7:151-154 doi: 10.1016/0169-5347(92)90208-S.

727 Poole KG, Bromley RG (1988) Interrelationships within a raptor guild in the central

728 Canadian Arctic. Can J Zool 66:2275-2287 doi: 10.1139/z88-338

729 Potapov E (1997) What determines the population density and reproductive success of rough-

730 legged buzzards, Buteo lagopus, in the Siberian tundra? Oikos 78:362-376 doi:

$731 \quad 10.2307 / 3546304$

732 Preisser EL, Bolnick DI, Benard MF (2005) Scared to death? The effects of intimidation and

733 consumption in predator-prey interactions. Ecology 86:501-509 doi: 10.1890/04-0719 
734 R Core Team (2013) R: A language and environment for statistical computing, version 3.0.2

735 Rebollo S, Pérez-Camacho L, García-Salgado G, Martínez-Hesterkamp S, Fernández-Pereira

736 JM, Rebollo M, Rebollo P, de la Montaña E (2011) Spatial relationship among northern

737 goshawk, Eurasian sparrowhawk and common buzzard: Rivals or partners? In: Zuberogoitia

738 I, Martínez JE (eds) Ecology and conservation of European forest-dwelling raptors.

739 Departamento de Agricultura de la Diputación Foral de Bizkaia, Bizkaia, pp 159-167

740 Reif V, Tornberg R, Jungell S, Korpimäki E (2001) Diet variation of common buzzards in

741 Finland supports the alternative prey hypothesis. Ecography 24:267-274 Accessible from:

$742 \quad$ www.jstor.org/stable/3683704

743 Ritchie EG, Johnson CN (2009) Predator interactions, mesopredator release and biodiversity

744 conservation. Ecol Lett 12:982-998 doi: 10.1111/j.1461-0248.2009.01347.x

745 Rutz C, Bijlsma RG (2006) Food-limitation in a generalist predator. Proc R Soc B Biol Sci

746 273:2069-2076 doi: 10.1098/rspb.2006.3507

747 Santangeli A, Lehtoranta H, Laaksonen T (2012) Successful voluntary conservation of raptor

748 nests under intensive forestry pressure in a boreal landscape. Anim Conserv 15:571-578 doi:

$749 \quad 10.1111 /$ j.1469-1795.2012.00551.x

750 Saurola P, Valkama J, Velmala W (2013) The Finnish bird ringing atlas vol I. Finnish

751 Museum of Natural History Luomus and Ministry of Environment, Helsinki

752 Schoener TW (1983) Field experiments on interspecific competition. Am Nat 122:240-285

753 Accessible from: www.jstor.org/stable/2461233 
754 Selås V, Steen OF, Johnsen JT (2008) Goshawk breeding densities in relation to mature 755 forest in southeastern Norway. For Ecol Manage 256:446-451 doi:

756 10.1016/j.foreco.2008.04.047

757 Sergio F, Hiraldo F (2008) Intraguild predation in raptor assemblages: A review. Ibis 758 150:132-145 doi: 10.1111/j.1474-919X.2008.00786.x

Sergio F, Marchesi L, Pedrini P (2003) Spatial refugia and the coexistence of a diurnal raptor with its intraguild owl predator. J Anim Ecol 72: 232-245 Accessible from: www.jstor.org/stable/3505298

Sergio F, Marchesi L, Pedrini P, Penteriani V (2007) Coexistence of a generalist owl with its 763 intraguild predator: Distance-sensitive or habitat-mediated avoidance? Anim Behav 74:16071616 doi: 10.1016/j.anbehav.2006.10.022

Sidorovich VE, Solovej IA, Sidorovich AA, Rotenko II (2008) Effect of felling on the distribution of rodents and their predators in a transitional mixed forest. Pol J Ecol 56:309321 Accessible from: www.pje.miiz.waw.pl prey communities: A review of field experiments. Ann Rev Ecol Syst 16:269-311 doi: 10.1146/annurev.es.16.110185.001413

Sulkava S, Linkola P, Lokki H (2006) The diet of the goshawk Accipiter gentilis during the nesting season in Häme (Southern Finland). Suomen Riista 52:85-96

774 interactions of a native mesocarnivore. Ecology 88:334-346 doi: 10.1890/0012- 
776 Tike, Information Centre of the Ministry of Agriculture and Forestry (2014) Utilised agricultural area [e-publication] www.stat.fi/til/kaoma/index_en.html

778 Tornberg R (2001) Pattern of goshawk Accipiter gentilis predation on four forest grouse

779 species in northern Finland. Wildl Biol 7:245-256 Accessible from:

780 www.wildlifebiology.com/Downloads/Article/342/En/7_4_tornberg.pdf

781 Tornberg R, Korpimäki E, Byholm P (2006) Ecology of the northern goshawk in

782 Fennoscandia. Stud Avian Biol 31:141-157 Accessible from:

783 www.planetofbirds.com/northern-goshawk-article-2

784 Valkama J, Vepsäläinen V, Lehikoinen A (2011) The Third Finnish Breeding Bird Atlas.

785 Finnish Museum of Natural History and Ministry of Environment.

786 http://atlas3.lintuatlas.fi/english (cited 12-Dec-2014)

787 van Lanen NJ, Franklin AB, Huyvaert KP, Reiser II RF, Carlson PC (2011) Who hits and

788 hoots at whom? Potential for interference competition between barred and northern spotted 789 owls. Biol Conserv 144:2194-2201 doi: 10.1016/j.biocon.2011.05.011

790 Venäläinen A, Tuomenvirta H, Pirinen P, Drebs A (2005) A basic Finnish climate data set

791 1961-2000 - description and illustrations. Reports - Finnish Meteorological Institute 5:1-27

792 Voous KH (1988) Owls of the Northern hemisphere. William Collins Sons \& Co, London

793 Widén P (1997) How, and why, is the goshawk (Accipiter gentilis) affected by modern forest

794 management in Fennoscandia. J Raptor Res 31:107-113

795 Ylitalo E (2013) Finnish statistical yearbook of forestry 2013. Finnish Forest Research

796 Institute, Vantaa 
797 Zuberogoitia I, Martínez JA, Zabala J, Martínez JE (2005) Interspecific aggression and nest-

798 site competition in a european owl community. J Raptor Res 39:156-159

799 Zuberogoitia I, Martínez JE, Zabala J, Martínez JA, Azkona A, Castillo I, Hidalgo S (2008)

800 Social interactions between two owl species sometimes associated with intraguild predation.

$801 \quad$ Ardea 96:109-113 doi: 10.5253/078.096.0112

802 Zuur AF, Ieno EN, Walker NJ, Saveliev AA, Smith GM (2009) Mixed effects models and

803 extensions in ecology with R. Springer, New York

804

805 Electronic Supplementary Material

806 The following Supporting Information is available for this article online:

807 Online Resource 1: Hawk territory dynamics

808 Online Resource 2: Additional information on materials and methods

809 Online Resource 3 Figures 1-5: Figures on the data

810 Online Resource 4: The AICs of the occupancy and breeding success GLMMs with different

811 goshawk threats

812 
813 Fig. 1 a) The study area North Karelia in eastern Finland. b) Territories of the common

814 buzzard (light grey dots, $\mathrm{n}=378$ ) and occupied territories of the goshawk (dark grey dots, $\mathrm{n}=$

815 192) in 1997-2009. Four black squares indicate the vole trapping sites. Exact within-site

816 trapping locations have varied during the study years, but this variation occurred within the

817 range of spatial synchrony of the vole cycle

818

819 Fig. 2 The probability of common buzzard territory occupancy along the goshawk threat,

820 based on the final occupancy-GLMM. Other variables were standardized in their means. The

821 line presents the predicted values and dots are the data points: $0=$ unoccupied, $1=$ occupied

822 common buzzard territories

823 
$824 \quad$ Figure 1.

825

826

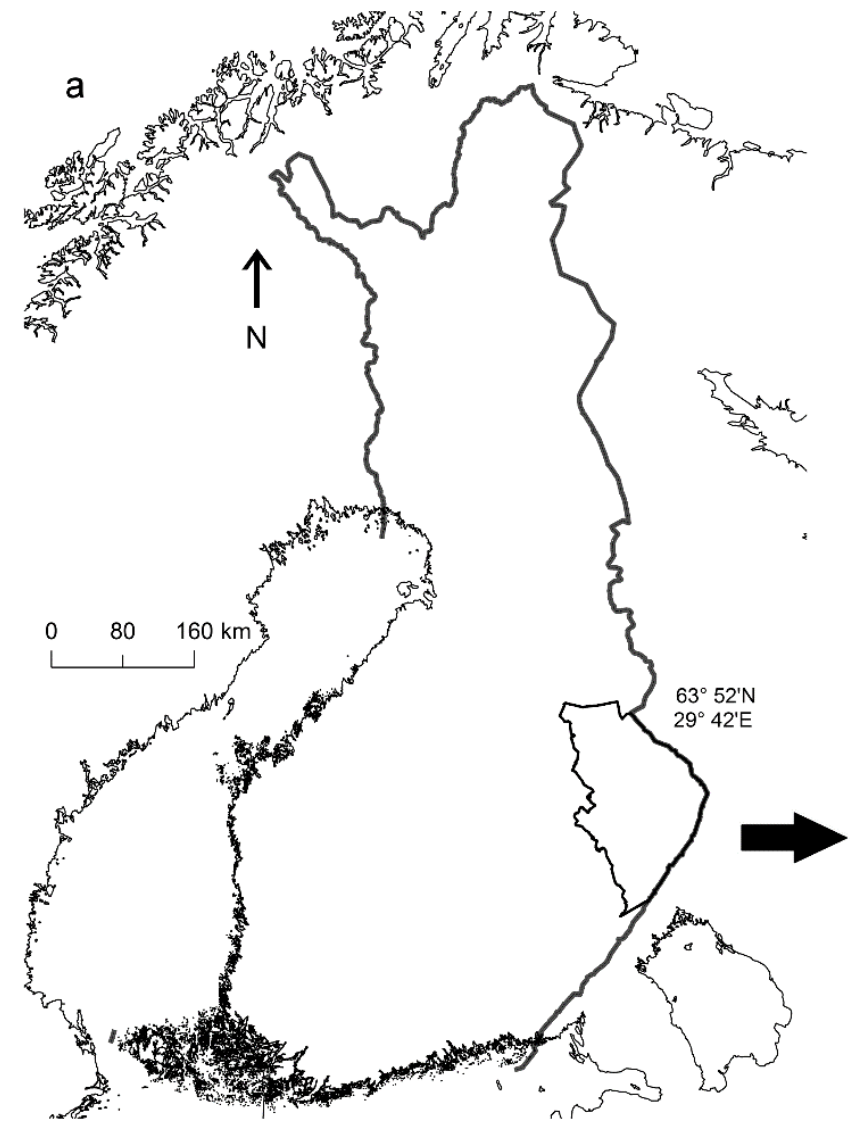

827

828

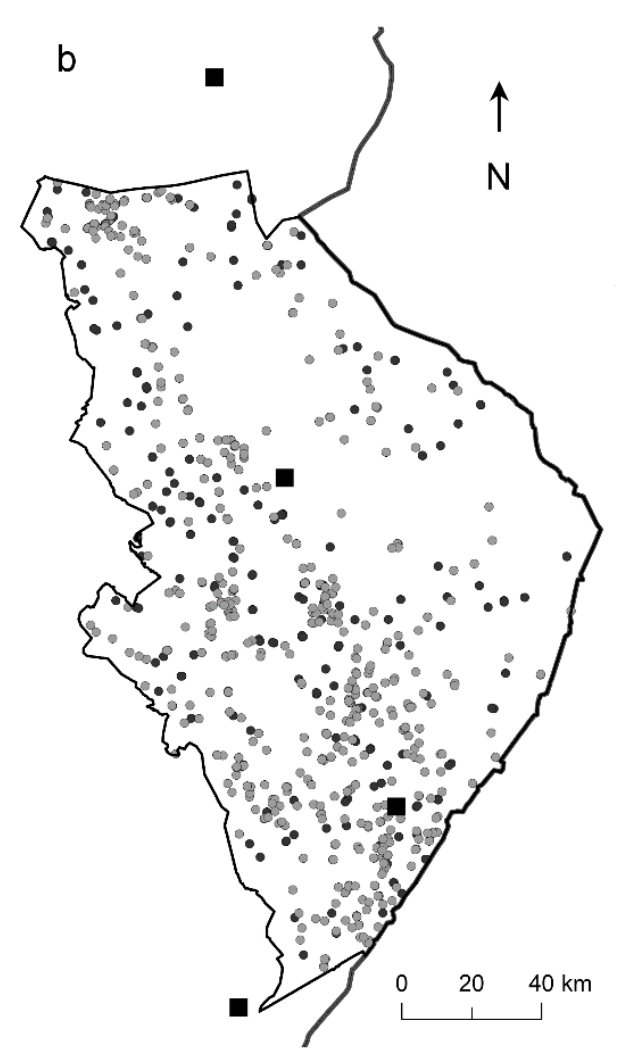


829 Figure 2.

830

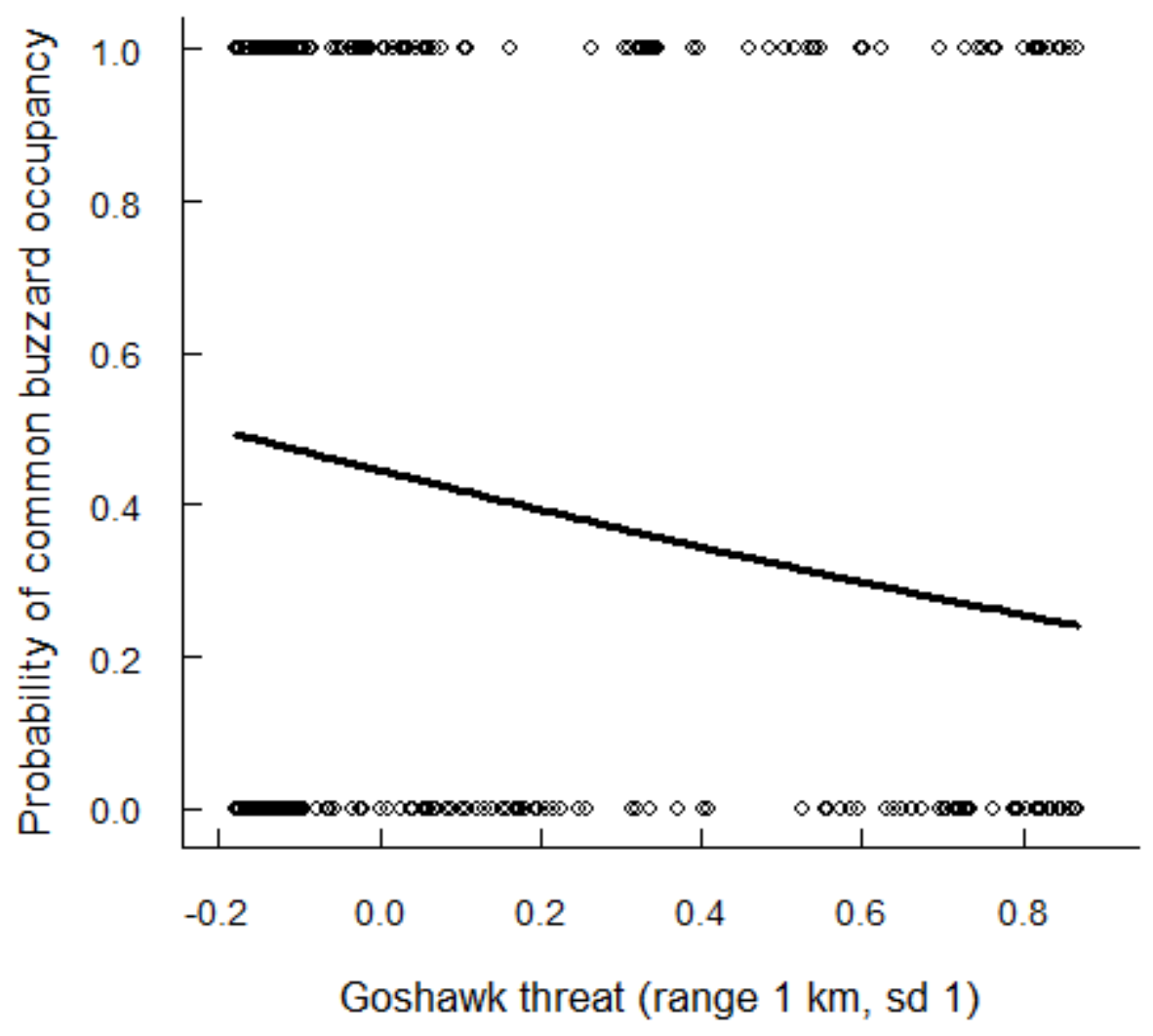

831

832

833 
834 Table 1 The logit-estimates of the final GLMM best explaining common buzzard territory occupancy. Model variables were standardized (mean

835 0, SD 0.5). Territory identity was used as a random effect (SE 2.17)

\begin{tabular}{|c|c|c|c|c|}
\hline Variable & Estimate & $\mathrm{SE}$ & $z$-value & $P(>|z|)^{\mathrm{a}}$ \\
\hline Intercept & -0.22 & 0.13 & -1.67 & 0.096 \\
\hline Vole index ${ }^{b}$ & -0.07 & 0.10 & -0.65 & 0.513 \\
\hline Goshawk threat $^{c}$ & -0.71 & 0.14 & -5.02 & $<0.001 * * *$ \\
\hline Grouseall-index $^{\mathrm{d}}$ & -0.32 & 0.11 & -2.99 & $0.003 * *$ \\
\hline Competitor in territory ${ }^{\mathrm{e}}$ & -2.86 & 0.41 & -6.94 & $<0.001 * * *$ \\
\hline Temperature, March $\left({ }^{\circ} \mathrm{C}\right)$ & -0.24 & 0.09 & -2.50 & $0.013 *$ \\
\hline Temperature, April $\left({ }^{\circ} \mathrm{C}\right)$ & -0.06 & 0.11 & -0.52 & 0.603 \\
\hline
\end{tabular}

$836 \quad{ }^{a}$ Significance levels: $* * *<0.001, * *<0.01, *<0.05$, n.s. $\geq 0.05$

$837{ }^{\mathrm{b}} \log _{\mathrm{e}}\left((\right.$ number of voles +1$)$ trap nights $\left.{ }^{-1}\right) \times 100$

$838{ }^{\mathrm{c}}$ Goshawk threat with a $1-\mathrm{km}$ range and $\mathrm{SD}=1$ (values $\left.0-1\right)$

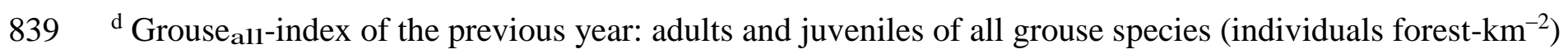

$840{ }^{\mathrm{e}}$ Estimate for the case that a territory has a competitor 
Table 2 The logit-estimates of the final GLMM best explaining the breeding success of the common buzzard. Model variables were standardized

\begin{tabular}{lcccc}
\hline Variable & Estimate & SE & $z$-value & $P(>|z|)^{\mathrm{a}}$ \\
\hline Intercept & 1.91 & 0.17 & 10.98 & $<0.001 * * *$ \\
Vole index $^{\mathrm{b}}$ & -0.15 & 0.37 & -0.40 & 0.689 \\
Goshawk threat $^{\mathrm{c}}$ & 0.27 & 0.35 & 0.78 & 0.436 \\
Grouse $_{\text {all-index }}{ }^{\mathrm{d}}$ & 0.50 & 0.36 & 1.37 & 0.171 \\
${\text { Temperature, April }\left({ }^{\circ} \mathrm{C}\right)}^{\text {Temperature, June }\left({ }^{\circ} \mathrm{C}\right)}$ & 0.68 & 0.32 & 2.15 & $0.032 *$ \\
Precipitation, June $(\mathrm{mm})$ & 0.22 & 0.38 & 0.58 & 0.561
\end{tabular}

\section{$844 \quad{ }^{a}$ Significance levels as in Table 1}

$845{ }^{\mathrm{b}} \log _{\mathrm{e}}\left((\right.$ number of voles +1$)$ trap nights $\left.{ }^{-1}\right) \times 100$

$846{ }^{\mathrm{c}}$ Goshawk threat with a $1-\mathrm{km}$ range and $\mathrm{SD}=1$ (values $\left.0-1\right)$

$847{ }^{\mathrm{d}}$ Grouse ${ }^{2}$-index of the current year: adults and juveniles of all grouse species (individuals forest-km ${ }^{-2}$ ) 
Electronic Supplementary Material ESM 1 to:

\section{Intraguild predation and competition impacts on a subordinate predator}

Heidi Björklund*, Andrea Santangeli, F. Guillaume Blanchet, Otso Huitu, Hannu Lehtoranta, Harto Lindén, Jari Valkama and Toni Laaksonen

* Contact information for the corresponding author:

Heidi Björklund

Finnish Museum of Natural History Luomus, P.O. Box 17, FI-00014 University of Helsinki, Finland

heidi.bjorklund@helsinki.fi, +358-2941-28844 
Hawk territory dynamics

Hawk nests are important resources for many raptors (McInvaille and Keith 1974; Pakkala et al. 2006; Jiménez-Franco et al. 2014). Nest construction demands time and energy (Jamieson and Seymour 1983; Margalida and García 1999) that can be saved when raptors re-use old stick nests. Moreover, some raptors (e.g. owls) do not construct nests themselves and they can be dependent on nest providers (McInvaille and Keith 1974; Springer and Kirkley 1978; Zhou et al. 2009).

In North Karelia, common buzzard nests were also occupied by the great grey owl, goshawk, honey-buzzard, Ural owl or common raven during the study period. However, the common buzzard territories were mostly occupied by the common buzzard only. The following numbers indicate how many other species have occupied the 378 common buzzard territories during the study period:

Common buzzard only: 225 territories

Common buzzard +1 species: 112 territories

Common buzzard +2 species: 33 territories

Common buzzard +3 species: 8 territories

Thus, $153(40.5 \%)$ of the common buzzard territories have also hosted other species.

Although even three other species have occupied the common buzzard territories, at most two species occupied a territory during the same breeding season. In the 153 territories, the territory occupancy has been dynamic, since a total of 220 changes in the territory occupier species were detected during the study period. These changes include that another species could enter in the territory (two species occupying the territory simultaneously), or occupancy alternated between the common buzzard and the other species in different years, 
or between the other species (e.g. from the great grey owl to the goshawk), possibly including years of unoccupancies in-between.

Perhaps the most interesting events are the changes of the occupier species in consecutive years. In a total of 27 occasions, the common buzzard had occupied a territory in the previous year, but not in the next year, when the great grey owl (13 occasions), goshawk (4), Ural owl (4), honey-buzzard (2), common raven (1), goshawk and great grey owl together (2) or honey-buzzard and great grey owl together (1) occupied the territory. Of these species, all except the honey-buzzard can occupy the territory before the common buzzard arrives from spring migration. Only four times, the common buzzard had occupied a territory in the previous year and continued to co-occupy the territory with another species in the next year. The co-occupier was then the goshawk (one occasion), great grey owl (1), Ural owl (1), or honey-buzzard (1). In all the four occasions, the common buzzard had no breeding attempt. There were more occasions when the common buzzard had not occupied the territory in the previous year but co-occupied it with another species in the next year. The common buzzard shared a territory this way with the goshawk 26 times (common buzzard then succeeded / failed / had no breeding attempt in 15 / 2 / 9 occasions, respectively), with the great grey owl five times $(2 / 2$ / 1), with the Ural owl once (0 / 1 / 0) and with the honey-buzzard once (1 / 0 / 0).

To compare with, we present the respective numbers for the goshawk territories. In 17 occasions, the goshawk had occupied a territory in the previous year, but the territory occupier changed in the next year. Then the territory occupier was the common buzzard in 12 occasions, great grey owl in four occasions, and honey-buzzard once. These species were probably not causing the disappearance of the goshawk, because the common buzzard and honey-buzzard arrive from migration after the goshawk has established its territory, and the great grey owl is presumably subdominant compared to the goshawk. In 13 occasions, the goshawk had occupied a territory in the previous year and continued to occupy it with 
another species in the next year. Then the co-occupier was the common buzzard eight times (common buzzard then succeeded / failed / had no breeding attempt in 6 / 1 / 1 occasions, respectively) and great grey owl five times. Of these 13 occasions, the goshawk succeeded / failed / had no breeding attempt in $10 / 2$ / 1 occasions.

\section{References}

Jamieson IG, Seymour NR (1983) Inter- and intra-specific agonistic behavior of ospreys (Pandion haliaetus) near their nest sites. Can J Zool - Rev Can Zool 61:2199-2202 doi: 10.1139/z83-290

Jiménez-Franco MV, Martínez JE, Calvo JF (2014) Patterns of nest reuse in forest raptors and their effects on reproductive output. J Zool 292:64-70 doi: 10.1111/jzo.12085

Margalida A, García D (1999) Nest use, interspecific relationships and competition for nests in the Bearded vulture Gypaetus barbatus in the Pyrenees: influence on breeding success. Bird Study 46:224-229 doi: 10.1080/00063659909461134

McInvaille WB, Keith LB (1974) Predator-prey relations and breeding biology of the great horned owl and red-tailed hawk in Central Alberta. Canadian Field-Naturalist 88:1-20

Pakkala T, Kouki J, Tiainen J (2006) Top predator and interference competition modify the occurrence and breeding success of a specialist species in a structurally complex forest environment. Ann Zool Fennici 43:137-164 Accessible from:

www.sekj.org/PDF/anzf43/anzf43-137.pdf

Springer MA, Kirkley JS (1978) Inter and intraspecific interactions between red-tailed hawks and great horned owls in Central Ohio. Ohio Journal of Science 78:323-328 Accessible from: http://hdl.handle.net/1811/22576

Zhou T, Wang H, Liu Y, Lei F, Gao W (2009) Patterns of magpie nest utilization by a nesting raptor community in a secondary forest. Prog Nat Sci 19:1253-1259 doi:

10.1016/j.pnsc.2009.03.006 
Electronic Supplementary Material ESM 2 to:

\section{Intraguild predation and competition impacts on a subordinate predator}

Heidi Björklund*, Andrea Santangeli, F. Guillaume Blanchet, Otso Huitu, Hannu Lehtoranta, Harto Lindén, Jari Valkama and Toni Laaksonen

* Contact information for the corresponding author:

Heidi Björklund

Finnish Museum of Natural History Luomus, P.O. Box 17, FI-00014 University of Helsinki, Finland

heidi.bjorklund@helsinki.fi, +358-2941-28844 
Titles below correspond to those in the article

Haw territory data

During a territory visit, bird-of-prey ringers and trained volunteers recorded the status of each of the alternative nests (i.e. whether the nest was decorated or unoccupied, the breeding result of a breeding attempt, the number of chicks, and the species occupying the nest). They also recorded information on the nest condition (e.g. good, fallen). The nests were frequently unoccupied for some years, leading to nest deterioration and even falling. Despite this, ringers continued their territory visits because after vacant periods, the same nests were refurbished or new alternative nests were built. However, alternative nests were sometimes lost (i.e. fallen definitely or nest tree cut), since they had been unoccupied for extensively long periods of time or were still unoccupied after a break of couple of years in territory inspection. In this case, we excluded the history of an alternative nest one year after the nest was proved fallen, or if the alternative nest was not found (presumably fallen) after a break in territory inspection.

Goshawk threat index

Nine goshawk threat surfaces were created across the study region for each year based on the location of occupied goshawk territories. The threat ranged from 0 to 1 on the surface, being highest at occupied goshawk territories. It was considered constant (threat $=1$ ) within a range of $1 \mathrm{~km}, 2 \mathrm{~km}$ or $3 \mathrm{~km}$ around an occupied goshawk nest. Of these ranges, $1 \mathrm{~km}$ corresponds to an average foraging distance of goshawks in a prey-rich environment (Penteriani et al. 2013) or "close" breeding distance between goshawks and common buzzards (Hakkarainen et al. 2004); $2 \mathrm{~km}$ is a half of the distance between neighbouring goshawks (Tornberg 2001); and $3 \mathrm{~km}$ is an average foraging distance of goshawks in prey-poor environment (Penteriani et al. 2013) or "distant" breeding distance between goshawks and common buzzards 
(Hakkarainen et al. 2004). Beyond the range, the threat decreased towards zero with increasing distance from the occupied goshawk nest. More specifically, flat-top (due to assumed constant threat within the range) bivariate Gaussian kernels were built with standard deviations $(\mathrm{SD})=1,3$ or 4 around each goshawk territories to measure the threat influence of goshawks. Different SDs regulated how deeply the threat decreased beyond the range $(1=$ deep, 4 = more gentle decrease). These distances were assumed, because we had no data on how far a threat effect of goshawks on common buzzards could reach. Gaussian distribution was assumed to represent the decrease whose exact shape is unknown, and bivariate kernels were used to create a landscape of threat (threat contours around goshawk territories). Each common buzzard territory then received nine different goshawk threat indices from the nine threat surfaces (constructed with combinations of three ranges and three SDs) based on the threat value on the surface at the common buzzard territory coordinates.

Grouse data

In July and August of each year, volunteers counted all grouse species along a 12-km-long equilateral triangle route (Lindén et al. 1996). In this time of the year females are still with their broods. Females with a brood were counted separately from adults without a brood. Grouse abundances were converted into species-specific grouse indices (individuals forest$\mathrm{km}^{-2}$ ). The most abundant grouse species in North Karelia were the black grouse and hazel grouse (Online Resource 2 Fig. 1). The capercaillie Tetrao urogallus was less abundant and the willow grouse Lagopus lagopus was rare. Populations of different grouse species were synchronous in North Karelia (Online Resource 2 Fig. 1; see also Lindström et al. 1996). For each wildlife triangle, an index of all adult and juvenile grouse (grouse ${ }_{\text {all }}$ ) and an index of all

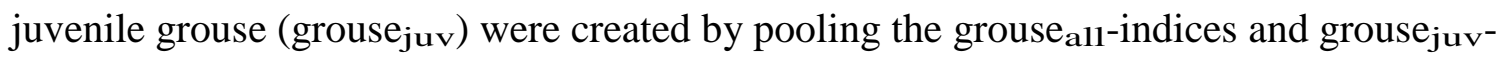
indices of all four grouse species, respectively (Online Resource 2 Fig. 1 \& Fig. 2). Pooling grouse indices of different species has been criticized, since the populations of different 
grouse can have separate impacts on predators (Tornberg et al. 2013). However, the aim of using the grouse indices was to measure the levels and distribution of grouse food in the hawk territories, and not species-specific functional effects of different grouse species on the predators.

\section{Figure 1}

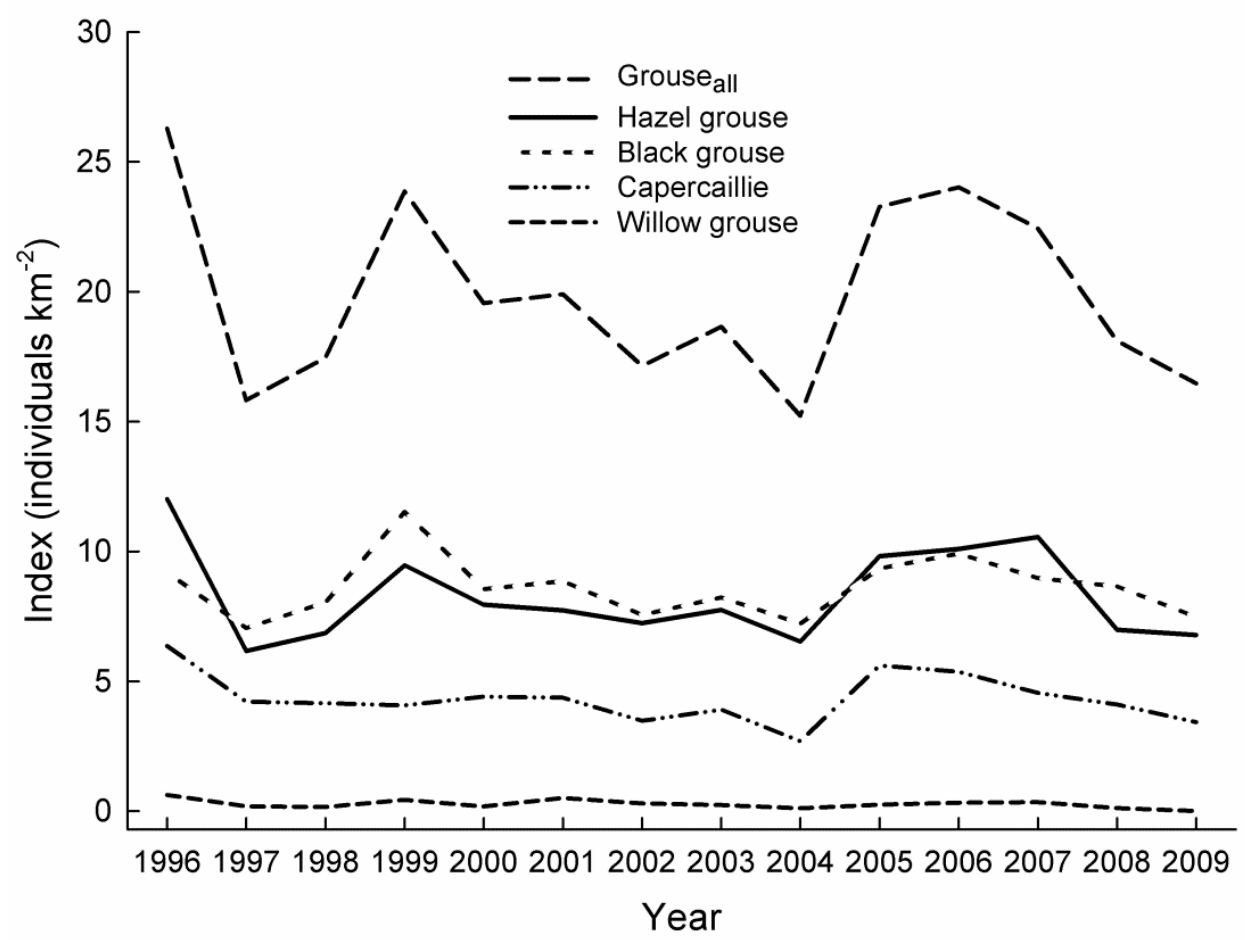

Fig. 1 The yearly averages of pooled grouse ${ }_{\text {all }}$ (adults + juveniles) indices (individuals forest$\mathrm{km}^{-2}$ ) of all grouse species in the wildlife triangle surveys in North Karelia, and the yearly

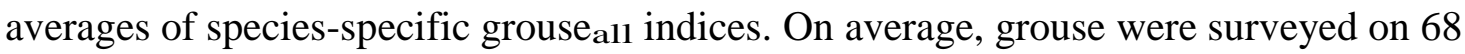
(range 60-79) wildlife triangles in each year 1996-2009 


\section{Figure 2}

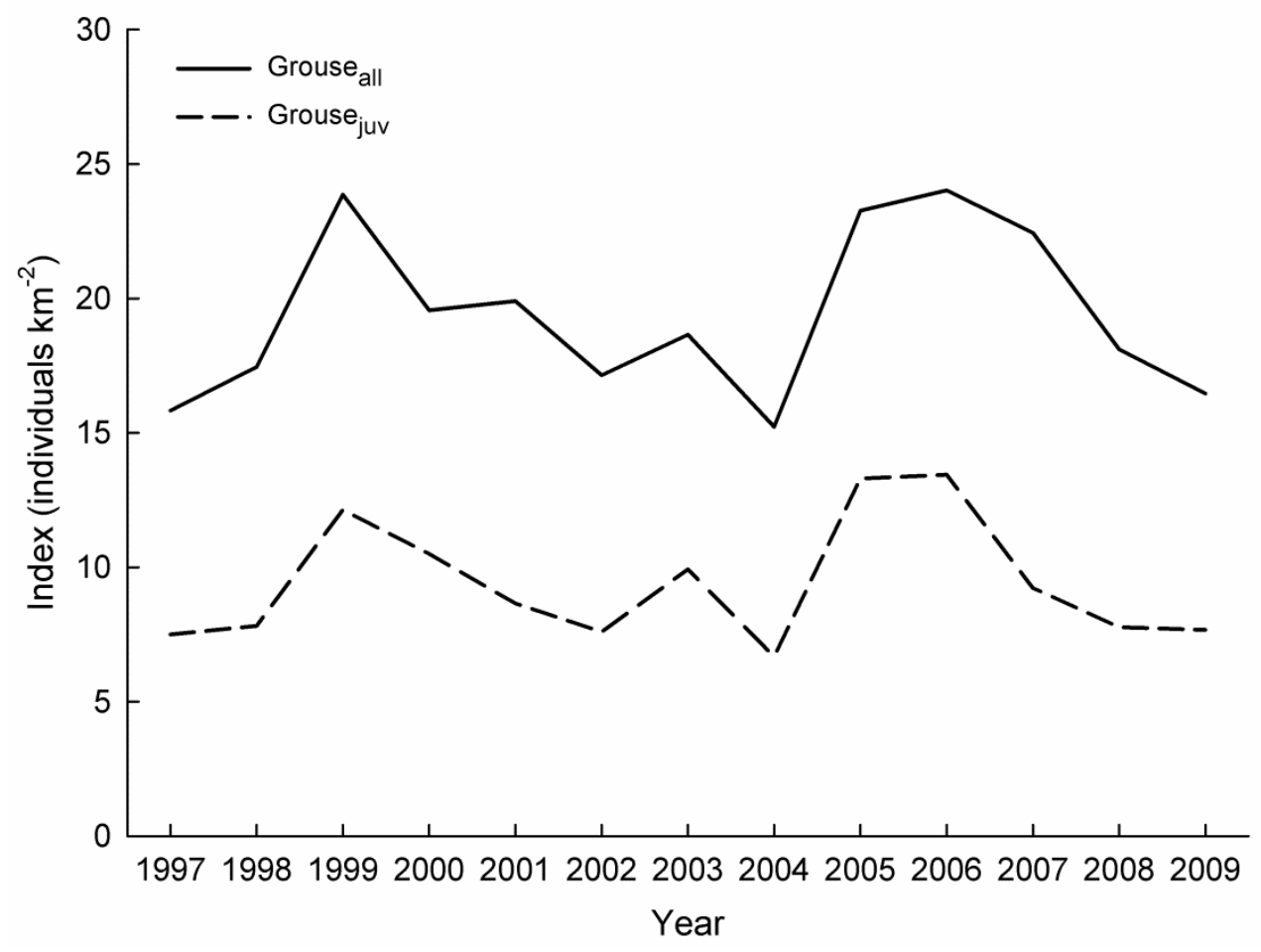

Fig. 2 The yearly averages of grouse ${ }_{a l l}$ and grouse ${ }_{j u v}$ (juveniles) indices (individuals forest$\mathrm{km}^{-2}$ ) in 1997-2009 in the wildlife triangle surveys in North Karelia

The capercaillie and the goshawk are sexually size-dimorphic (Cramp and Simmons 1980; Lindén 1981), and the capercaillie has also a biased sex ratio (males $40 \%$, females $60 \%$; Helle et al. 1999). The large capercaillie cocks are in general too big as a prey for the male goshawks (which are smaller than the females), and the predation rates of female goshawks on the capercaillie are also rather low (Tornberg 1997, 2001; Tornberg et al. 2006). We assumed that female goshawks (50\% of the breeding goshawks) can predate the capercaillie hen only (60\% of adult capercaillies), and therefore, the adult capercaillie index (included in the grouse ${ }_{a 11}$-index $)$ was multiplied by $0.3(=0.5 \times 0.6$; the proportions of female breeding goshawks and adult capercaillie hen, respectively). The corrected grouseall-index was then used in the analyses. 
Wildlife triangles from North Karelia and within a 50-km buffer-zone outside the North Karelia (except beyond the country border) were included. Data were thus gathered yearly from an average of 133 (range $=121-150)$ wildlife triangles. An inverse distance weight method (IDW) was used to generalize the grouse indices from the wildlife triangles to nonsampled areas (areas without triangles) in ArcGIS 10 (Esri, USA). First a raster was created with a grid-cell size of $100 \times 100 \mathrm{~m}$ over the study area. Wildlife triangles were then searched for with a radius of $50 \mathrm{~km}$ from each grid-cell in each year, and interpolation for each gridcell was based on grouse indices of at minimum four wildlife triangles. The IDW gives less weight for grouse indices from more distant wildlife triangles, and a power of two was used as a value regulating the decrease of grouse index values with an increasing distance.

Interpolations produced for each year a grouse al1- and a grouse ${ }_{j u v}$-layer (Online Resource 2

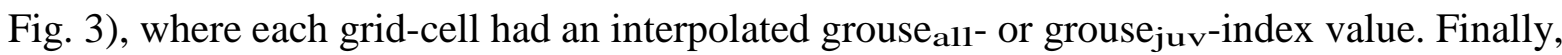
the interpolated grouse-indices were extracted into hawk territories situating in the respective grid-cells. 


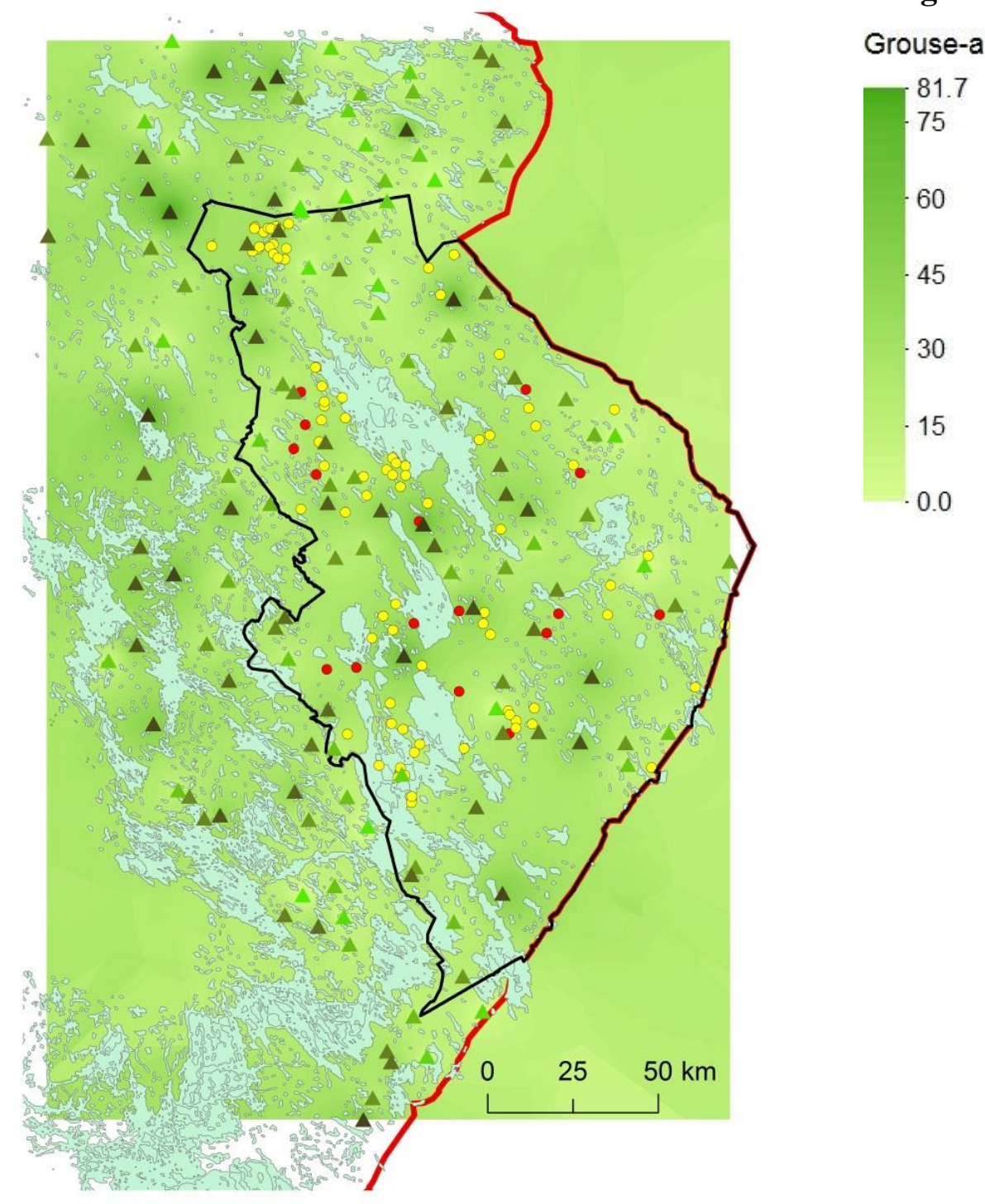

Figure 3

Grouse-all index in 1999

81.7

60 45

30

15

0

Fig. 3 The interpolation of grouse al1-indices (individuals forest- $\mathrm{km}^{-2}$ ) in 1999. The IDWinterpolation was based on grouse al1-indices of 143 wildlife triangles situating in North Karelia (delineated with the black outline; the red line represents the border between Finland and Russia) and within 50 kilometres around North Karelia. Triangles: wildlife triangles,

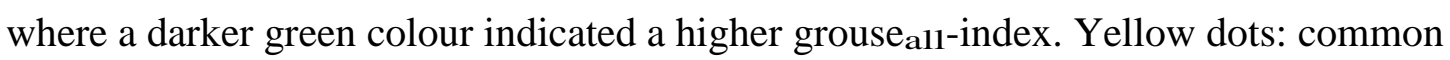
buzzard territories (occupied and unoccupied, $\mathrm{n}=84$ ). Red dots: goshawk territories (occupied, $\mathrm{n}=20$ ) in 1999. Map: National Land Survey of Finland, 2010 


\section{References}

Cramp S, Simmons KEL (1980) Handbook of the birds of Europe, the Middle East and North Africa: The birds of the Western Palearctic, hawks to bustards. Oxford University Press, Oxford

Hakkarainen H, Mykrä S, Kurki S, Tornberg R, Jungell S (2004) Competitive interactions among raptors in boreal forests. Oecologia 141:420-424 doi: 10.1007/s00442-004-1656-6

Helle H, Kurki S, Lindén H (1999) Change in the sex ratio of the Finnish capercaillie Tetrao urogallus population. Wildl Biol 5:25-31

Lindén H (1981) Growth rates and early energy requirements of captive juvenile capercaillie, Tetrao urogallus. Finnish Game Research 39:53-67

Lindén H, Helle E, Helle P, Wikman M (1996) Wildlife triangle scheme in Finland: methods and aims for monitoring wildlife populations. Finnish Game Research 49:4-11

Lindström J, Ranta E, Lindén H (1996) Large-scale synchrony in the dynamics of capercaillie, black grouse and hazel grouse populations in Finland. Oikos 76:221-227 Accessible from: www.jstor.org/stable/3546193

Penteriani V, Rutz C, Kenward R (2013) Hunting behaviour and breeding performance of northern goshawks Accipiter gentilis, in relation to resource availability, sex, age and morphology. Naturwissenschaften 100:935-942 doi: 10.1007/s00114-013-1093-7

Tornberg R (1997) Prey selection of the goshawk Accipiter gentilis during the breeding season: The role of prey profitability and vulnerability. Ornis Fenn 74:15-28 Accessible from: www.ornisfennica.org/search.htm 
Tornberg R (2001) Pattern of goshawk Accipiter gentilis predation on four forest grouse species in northern Finland. Wildl Biol 7:245-256 Accessible from:

www.wildlifebiology.com/Downloads/Article/342/En/7_4_tornberg.pdf

Tornberg R, Korpimäki E, Byholm P (2006) Ecology of the northern goshawk in Fennoscandia. Stud Avian Biol 31:141-157 Accessible from:

www.planetofbirds.com/northern-goshawk-article-2

Tornberg R, Lindén A, Byholm P, Ranta E, Valkama J, Helle P, Lindén H (2013) Coupling in goshawk and grouse population dynamics in Finland. Oecologia 171:863-872 doi:

$10.1007 / \mathrm{s} 00442-012-2448-\mathrm{Z}$ 
Electronic Supplementary Material ESM 3 to:

\section{Intraguild predation and competition impacts on a subordinate predator}

Heidi Björklund*, Andrea Santangeli, F. Guillaume Blanchet, Otso Huitu, Hannu Lehtoranta, Harto Lindén, Jari Valkama and Toni Laaksonen

* Contact information for the corresponding author:

Heidi Björklund

Finnish Museum of Natural History Luomus, P.O. Box 17, FI-00014 University of Helsinki, Finland

heidi.bjorklund@helsinki.fi, +358-2941-28844 


\section{Figure 1}
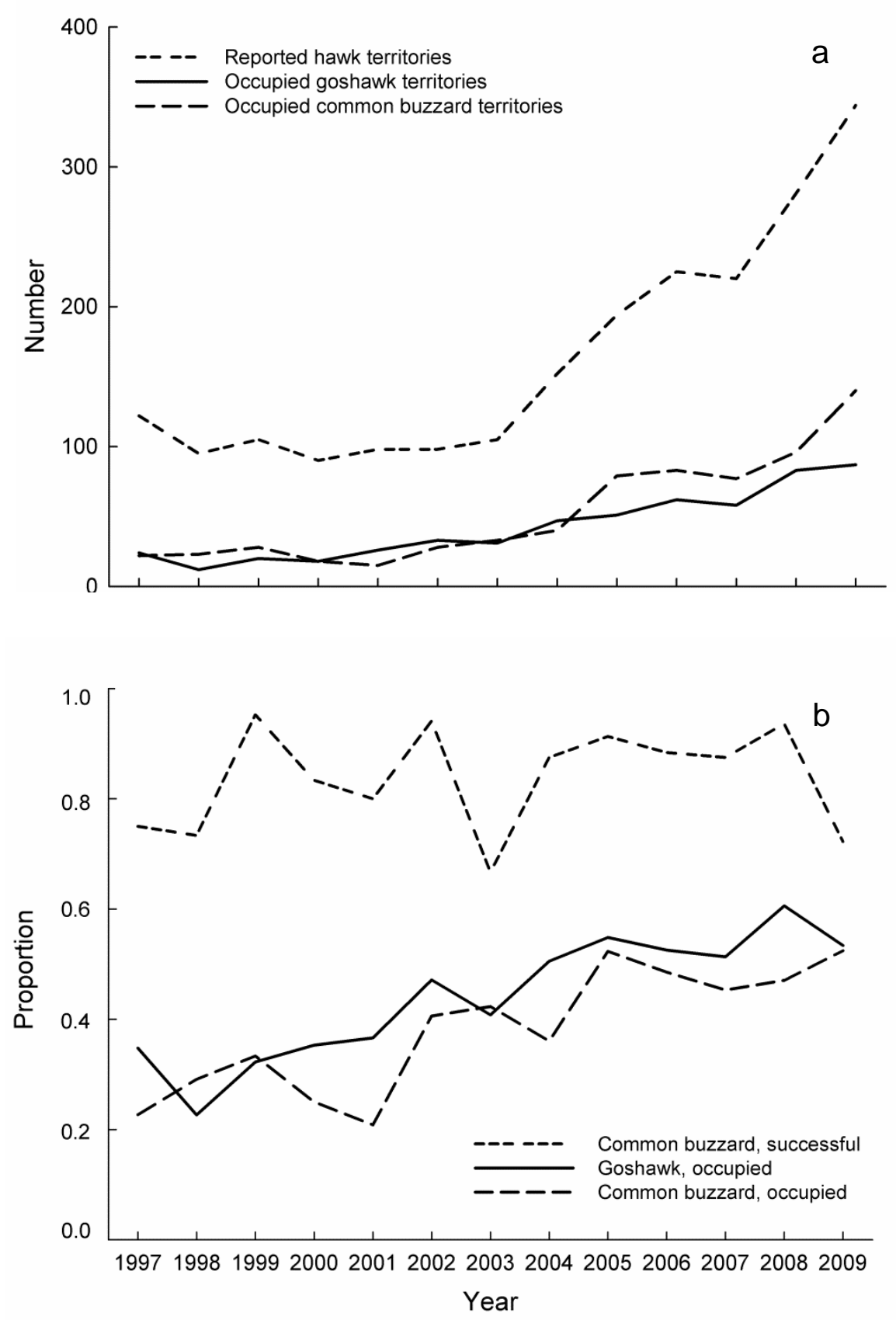

Fig. 1 a) The number of reported territories of the common buzzard, goshawk and honeybuzzard, and numbers of occupied territories of the common buzzard and goshawk in North Karelia in 1997-2009. Search effort increased in early 2000s and as a consequence, the numbers of occupied common buzzard and goshawk territories increased. b) The proportions of occupied common buzzard and goshawk territories increased in 1997-2009, partly because newly found territories were often occupied. The proportion of successful breeding attempts of the common buzzard was not increasing 


\section{Figure 2}

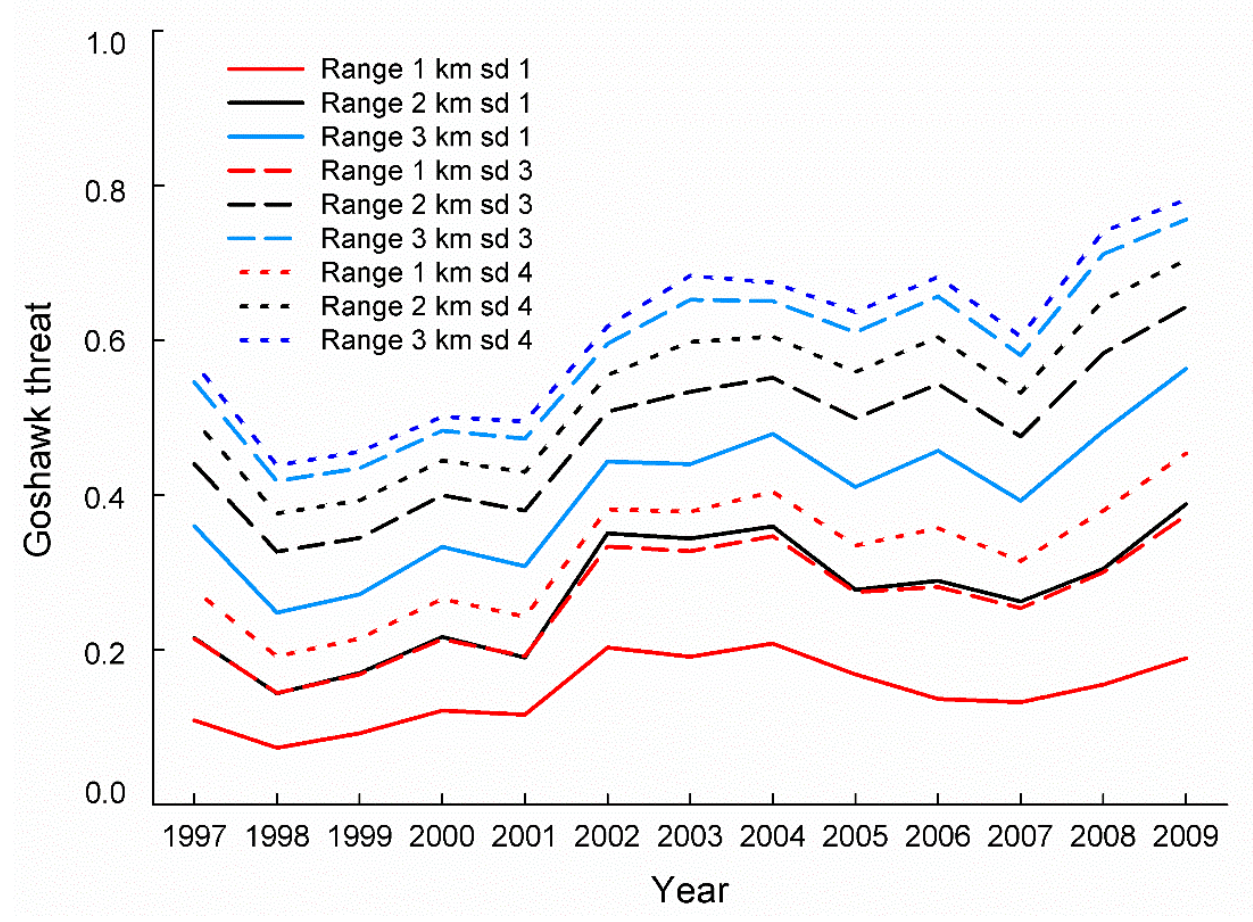

Fig. 2 The average goshawk threat indices in the common buzzard territories in 1997-2009. The goshawk threat ranged from 0 to 1 , being highest (threat $=1$ ) at occupied goshawk nests and constant within a specified range. Beyond the range, the threat decreased towards zero with increasing distance from the occupied goshawk nest. Different standard deviations (SD) regulated how deeply the threat decreased beyond the range. Nine different goshawk threat indices were created by using combinations of three range distances $(1 \mathrm{~km}, 2 \mathrm{~km}, 3 \mathrm{~km})$ and three standard deviations $(1,3,4)$ 


\section{Figure 3}
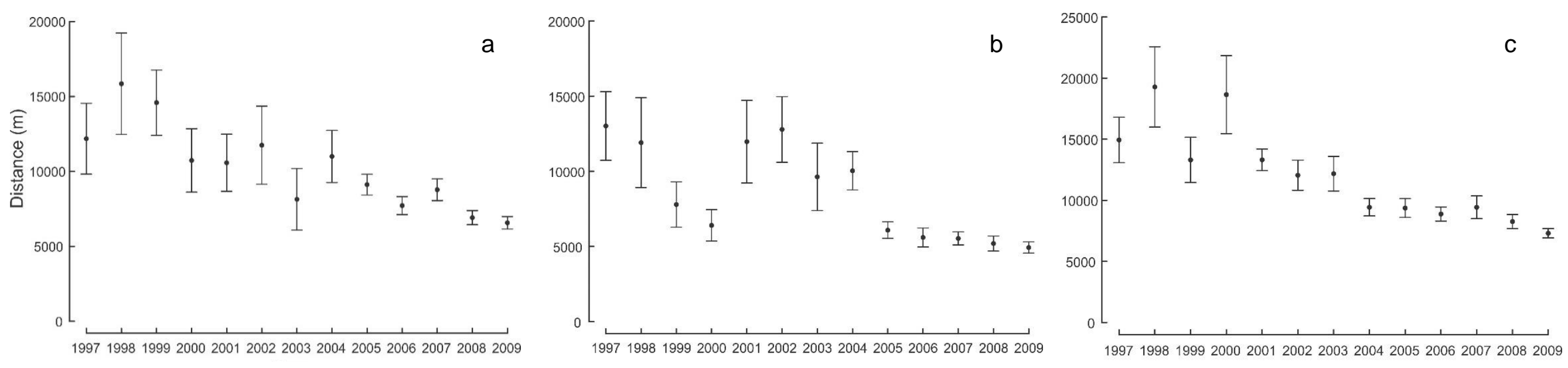

Fig. $3 \mathrm{a}-\mathrm{c}$ ) Average nearest-neighbour distances \pm standard errors of occupied territories during the study period. a) Interspecific nearest-neighbour distances (NNDs) of the common buzzard and goshawk. Interspecific pairs were not included if they were occupying the same territory during the same year. The minimum distance between the occupied common buzzard and goshawk territories was $398 \mathrm{~m}$. b) Intraspecific NNDs of the common buzzard territories. The minimum distance between occupied common buzzard territories was $712 \mathrm{~m}$. c) Intraspecific NNDs of the goshawk territories, with a minimum distance of $1524 \mathrm{~m}$ between occupied goshawk territories. Note the different scale at the y-axis. Minimum NNDs are often longer for intraspecific than interspecific territories since intraspecific competition is usually stronger than interspecific (Schmutz et al. 1980; Connell 1983; Katzner et al. 2003). Nearest-neighbour distances, calculated with R-package spatstat (Baddeley and Turner 2013), decreased during the years because new territories were found between the known territories 


\section{Figure 4}

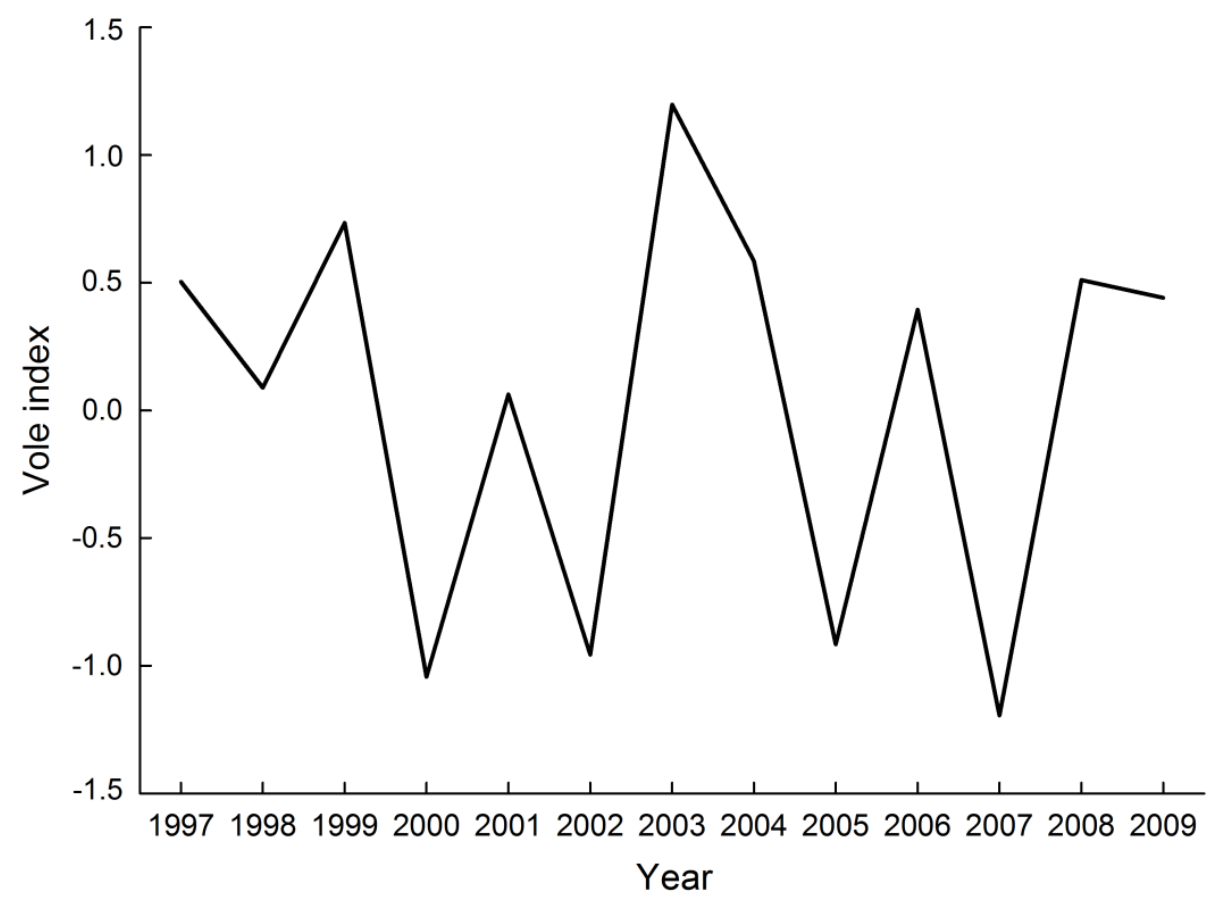

Fig. 4 The average of standardized vole abundance indices $(\log (($ number of voles +1$)$ trap nights $\left.^{-1}\right) \times 100$ ) of the four trapping sites (see Fig. 1b in the article) in 1997-2009 


\section{Figure 5}

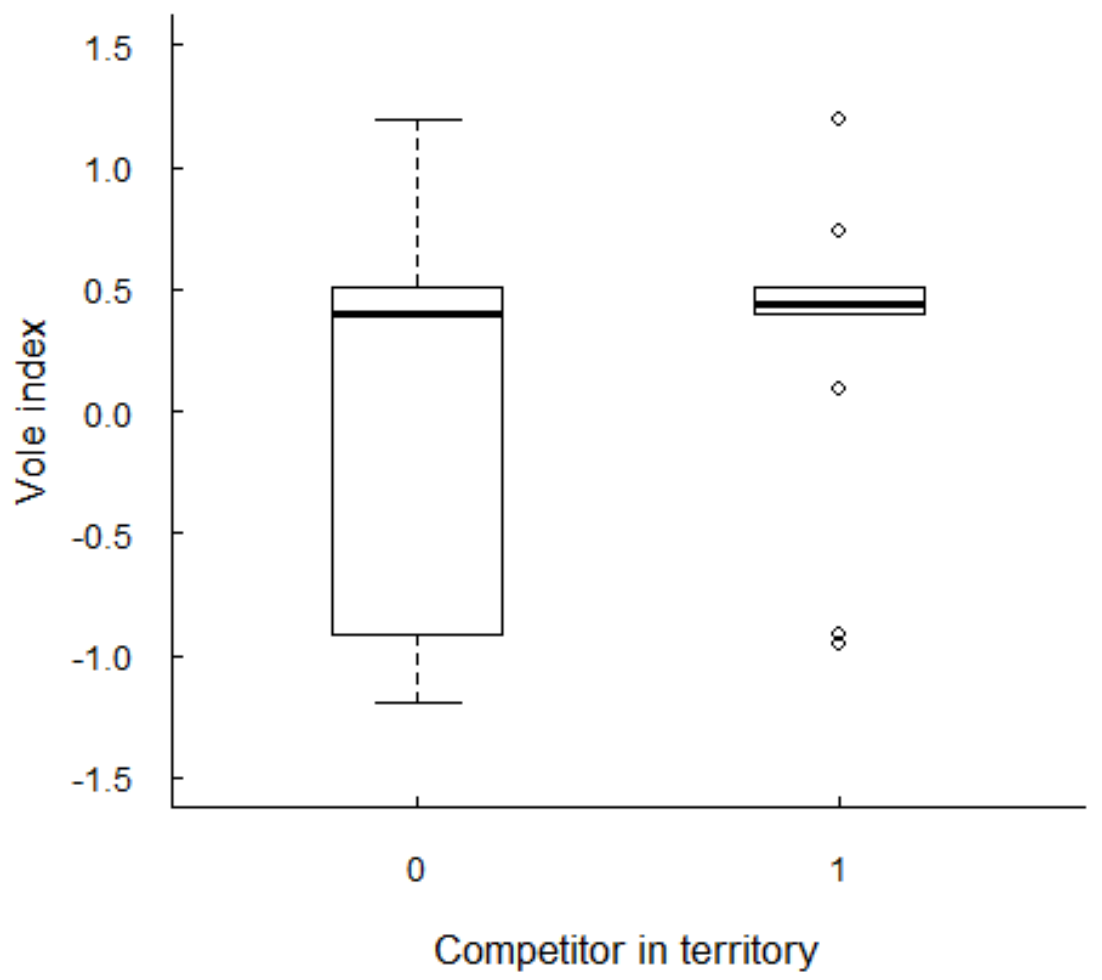

Fig. 5 The average vole index $\left(\log \left((\right.\right.$ number of voles +1$)$ trap nights $\left.\left.^{-1}\right) \times 100\right)$ when common buzzard territories had a competitor (1) or had no competitor (0). The figure includes only territories that had a competitor at least in one year (48 territories). Presence-absence data of competitors was included from all years from these territories. Possible competitors were the great grey owl, Ural owl or common raven (in 49, 10 and one occasion, respectively)

\section{References}

Baddeley A, Turner R (2013) Package 'spatstat', version 1.35-0

Connell JH (1983) On the prevalence and relative importance of interspecific competition:

Evidence from field experiments. Am Nat 122:661-696 Accessible from: www.jstor.org/stable/2460847

Katzner TE, Bragin EA, Knick ST, Smith AT (2003) Coexistence in a multispecies assemblage of eagles in Central Asia. Condor 105:538-551 
Schmutz JK, Schmutz SM, Boag DA (1980) Coexistence of three species of hawks (Buteo spp.) in the prairie-parkland ecotone. Can J Zool 58:1075-1089 
Electronic Supplementary Material ESM 4 to:

\section{Intraguild predation and competition impacts on a subordinate predator}

Heidi Björklund*, Andrea Santangeli, F. Guillaume Blanchet, Otso Huitu, Hannu Lehtoranta, Harto Lindén, Jari Valkama and Toni Laaksonen

* Contact information for the corresponding author:

Heidi Björklund

Finnish Museum of Natural History Luomus, P.O. Box 17, FI-00014 University of Helsinki, Finland

heidi.bjorklund@helsinki.fi, +358-2941-28844 
Table 1 The AICs of the GLMMs where common buzzard occupancy or breeding success was modelled using one of the nine goshawk threats as an explanatory variable. The goshawk threat of the GLMM with the lowest AIC (marked with bold) was selected for further occupancy and breeding success analyses. Since AICs of all breeding success GLMMs were within $\leq 2$ of the best model, the subsequent breeding success analyses were also conducted with these goshawk threats

\section{AIC}

\begin{tabular}{lll} 
Goshawk threat & Occupancy & Breeding success \\
\hline range $1 \mathrm{~km}$, SD 1 & $\mathbf{3 4 2 3 . 8 3}$ & $\mathbf{3 3 7 . 2 7}$ \\
range $2 \mathrm{~km}$, SD 1 & 3440.00 & 337.78 \\
range $3 \mathrm{~km}$, SD 1 & 3447.81 & 337.55 \\
range $1 \mathrm{~km}$, SD 3 & 3438.71 & 337.78 \\
range $2 \mathrm{~km}$, SD 3 & 3447.17 & 337.75 \\
range $3 \mathrm{~km}$, SD 3 & 3447.08 & 337.78 \\
range $1 \mathrm{~km}$, SD 4 & 3443.31 & 337.77 \\
range $2 \mathrm{~km}$, SD 4 & 3447.01 & 337.79 \\
range $3 \mathrm{~km}$, SD 4 & 3446.81 & 337.77 \\
\hline
\end{tabular}

